\title{
AVALIAÇÃO DE SISTEMAS DE PRO DUÇÃO DE CAFÉ NA REGIÃO SUL DE MINAS GERAIS: UM MODELO DE ANÁLISE DE DECISÃO
}

\section{GLAUCO RODRIGUES CARVALHO}

Dissertação apresentada à Escola Superior de Agricultura "Luiz de Queiroz", Universidade de São Paulo, para obtenção do título de Mestre em Ciências, Área de Concentração: Economia Aplicada.

\author{
P I R A C I C A B A \\ Estado de São Paulo - Brasil
}

Novembro - 2002 


\title{
AVALIAÇÃO DE SISTEMAS DE PRODUÇÃO DE CAFÉ NA REGIÃO SUL DE MINAS GERAIS: UM MODELO DE ANÁLISE DE DECISÃO
}

\section{GLAUCO RODRIGUES CARVALHO}

Bacharel em Ciências Econômicas

\section{Orientador: Prof. Dr. FERNANDO CURI PERES}

\author{
Dissertação apresentada à Escola Superior de \\ Agricultura "Luiz de Queiroz", Universidade \\ de São Paulo, para obtenção do título de \\ Mestre em Ciências, Área de Concentração: \\ Economia Aplicada.
}

\author{
P I R A C I C A B A \\ Estado de São Paulo - Brasil
}

Novembro - 2002 


\section{Dados Internacionais de Catalogação na Publicação (CIP) DIVISÃO DE BIBLIOTECA E DOCUMENTAÇÃO - ESALQ/USP}

\section{Carvalho, Glauco Rodrigues}

Avaliação de sistemas de produção de café na região sul de Minas Gera is : um modelo de análise de decisão / Glauco Rodrigues Carvalho. - - Piracic aba, 2002.

$68 \mathrm{p}$.

Dissertação (mestrado) - - Escola Superior de Agricultura Luiz de Queiroz, 2002.

Bibliografia.

1. Café 2. Minas Gerais 3. Região sul 4. Sistema de produção 5. Teoria de decisão I. Título

CDD 338.17373

"Permitida a cópia total ou parcial deste documento, desde que citada a fonte - $\mathrm{O}$ autor" 


\section{AGRADECIMENTOS}

Aos meus pais, que sempre me deram apoio e procuraram mostrar a importância dos estudos. À minha mãe, sempre presente nos momentos mais difíceis. Aos meus irmãos CG e Gui, e em especial ao Gladyston, pela colaboração técnica na realização deste trabalho. À sempre atenciosa Carmem por sua presença em nossa família. Aos meus avós e tios que de alguma forma participaram mesmo distantes. Às cunhadas Dani e Helo, em especial à Lucine, pelo apoio com seus conhecimentos agronômicos

Ao tio Fernando, Helsinho e madrinha Miriam que auxiliaram no fornecimento de informações valiosas. Ao engenheiro agrônomo Josué Figueiredo, pelos dados disponibilizados.

Aos pesquisadores da Epamig (Lavras e Machado) e da Emater (Lavras), que tanto ajudaram na realização dos grupos focais. A todos os cafeicultores e agrônomos que auxiliaram e participaram da pesquisa qualitativa.

Aos professores Adriano e Fernando pela orientação, paciência e amizade, demostrados durante todo o curso. Sem sua ajuda certamente a condução desse trabalho seria muito mais difícil.

Ao professor Carlos Bacha, pelo convívio, amizade e aprendizado ao longo do curso. Aos professores Alexandre e Evaristo pelas críticas e sugestões, que foram importantes para a qualidade desse trabalho. 
À USP e ao CNPq, que ofereceram o suporte necessário para o bom aproveitamento do curso de pós-graduação.

A todos os professores do Departamento de Economia, Administração e Sociologia da ESALQ/USP, que contribuíram para meu aprendizado.

Aos funcionários do Departamento de Economia, Administração e Sociologia da ESALQ/USP pela atenção e dedicação demonstrada: Maielli, Cris, Helena, Márcia, Pedro, Valdeci, Elenice, Maria Helena, Ligiana. Em especial a amiga Lú, pela amizade. Todos eles foram muito importantes e tornaram o curso mais agradável.

Aos amigos de todas as horas: Cadu e Gonça. Aos demais colegas da turma do mestrado, Conchas, Dilson, Valeriana, Viviane, Paula, Cris, .... Aos alunos da pós, que também tornaram o curso mais agradável: Robson, Daltro, Ary (os CPs) Leopoldo, Fabiana, Carla, Cassiana, Casimiro, Jaenes, Cândida, Vitor, Elisson, Alê, e todos os demais que a falta de espaço me impede de citar, mas que ficarão em minhas melhores lembranças.

Aos veteranos amigos da república, Ona, Zé, Fábio, Marcelo, Emerson, em especial ao grande Bruno. Vocês proporcionaram uma amizade muito agradável e divertida. Aos novos amigos da república Juju, Doug, Daniel, em especial ao companheiro Mim. Como não poderia esquecer, àfamosa dona Dí, mãe de todos.

Aos alunos do curso de graduação da Esalq/Usp, com os quais tive a oportunidade de ensinar e aprender.

À Clesiane, que mesmo distante sempre me transmitiu muito carinho, tornou os maus momento agradáveis e os bons momentos ainda melhores.

À Deus, pela saúde, paz e alegria. 


\section{SUMÁRIO}

Página

LISTA DE FIGURAS …....................................................................... vii

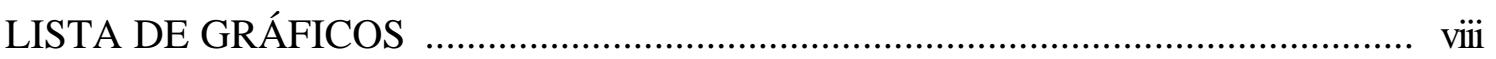

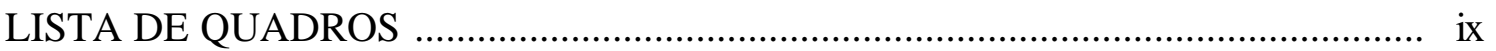

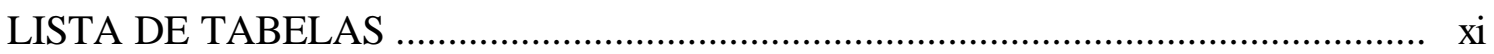

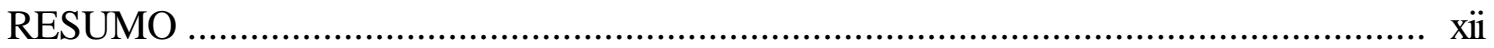

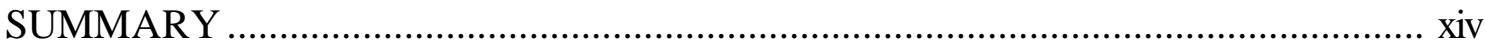

1 INTRODUÇÂA

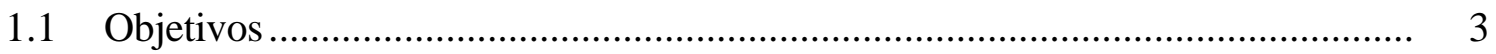

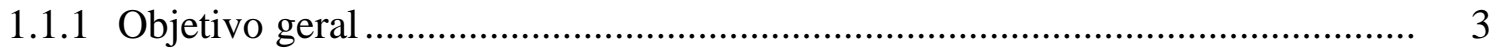

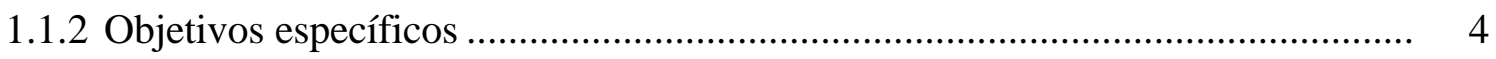

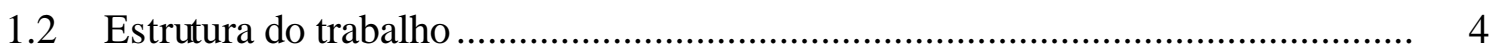

1.3 A importância do café no Brasil .................................................................... 5

2 REVISÃO DE LITERATURA ............................................................ 7

2.1 Sistemas de produção de café ................................................................. 7

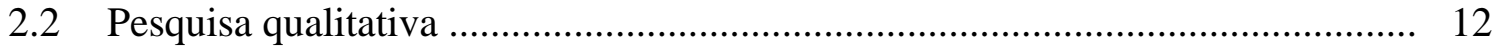

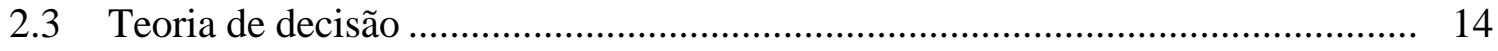

2.3.1 O processo de implementação de análise e engenharia de decisão ..................... 14

2.3.2 Modelos de maximização do valor esperado ................................................ 15

2.3.3 Modelos de maximização da utilidade esperada .......................................... 15

2.3.4 Diagramas de decisão .......................................................................... 18

2.3.5 Algumas aplicações da teria de decisão........................................................ 19 
3 IDENTIFICAÇÃO DE QUESTÕES RELEVANTES EM SISTEMAS DE PRODUÇÃO DE CAFÉ NA REGIÃO SUL DE MINAS GERAIS ATRAVÉS DE GRUPOS FOCAIS...................................................... 22

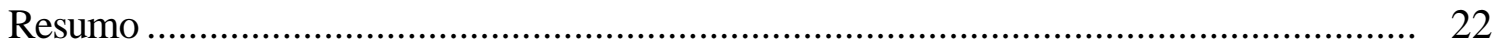

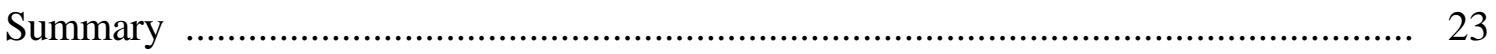

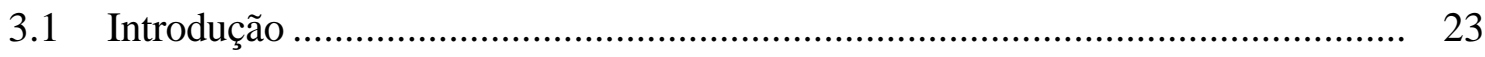

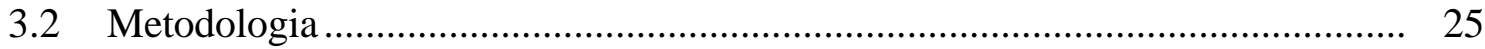

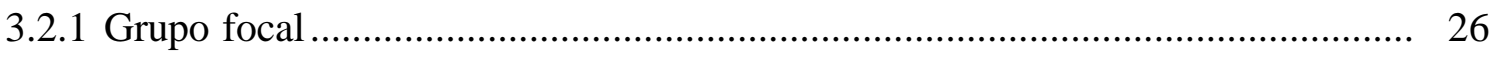

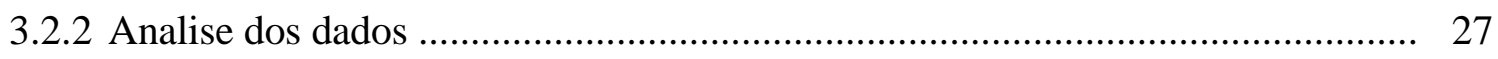

3.2.3 Procedimentos metodológicos ................................................................. 28

3.3 Resultados e Discussão ............................................................................. 31

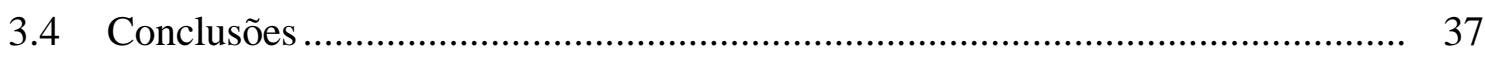

4 SISTEMAS DE PROCESSAMENTO DE CAFÉ NO SUL DE MINAS GERAIS: UM MODELO DE ANÁLISE DE DECISÃO .................. 39

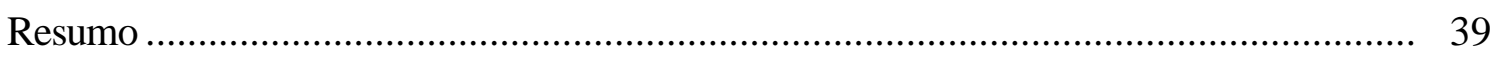

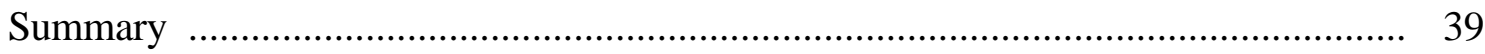

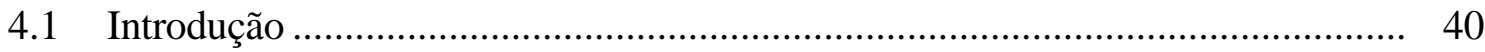

4.1.1 O sistema de preparo do café .................................................................. 40

4.2 Revisão de Literatura ........................................................................... 42

4.2.1 O processo de implementação de análise e engenharia de decisão ..................... 42

4.2.2 Diagramas de decisão ....................................................................... 45

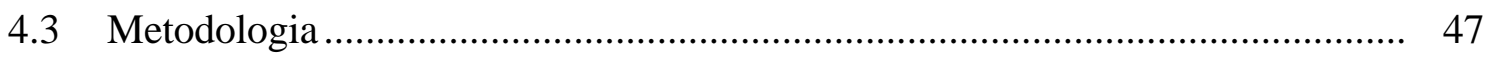

4.3.1 Modelo analítico ................................................................................. 47

4.3.2 Procedimentos para obtenção dos dados ................................................... 51

4.3.3 Fazenda "Café Sul de Minas" ........................................................................ 53

4.4 RESULTADOS E DISCUSSÃO............................................................ 53

4.4.1 Modelo de maximização do valor esperado ................................................. 53

4.4.2 Modelo de maximização da utilidade esperada ............................................ 55

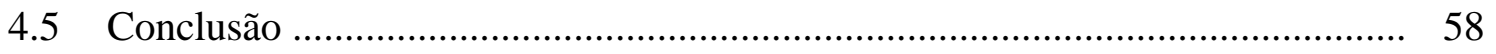

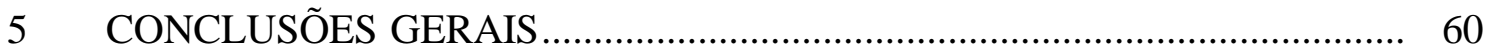


REFERÊNCIAS BIBLIOGRÁFICAS ………………………………............ 62 


\section{LISTA DE FIGURAS}

Página

1 Esquema de processamento do café ................................................................ 42

2 Esquema de orientação no processo de análise e engenharia de decisões .............. 44

3 Elementos gráficos dos diagramas de decisão ........................................... 47

4 Apresentação do modelo de decisão para sistemas de preparo do café ................... 48 


\section{LISTA DE GRÁFICOS}

Página

1 Coeficiente de aversão relativo ao risco e valores de $p$..................................... 18

2 Grau de aversão relativo ao risco e utilidade esperada para os sistemas de processamento do café ........................................................................ 58 


\section{LISTA DE QUADROS}

Página

1 Roteiro de discussão aplicado aos primeiros grupos focais ................................ 29

2 Roteiro de discussão utilizado após a segunda reunião........................................ 30

3 Caracterização dos sistemas de produção de café .............................................. 33

4 Sistemas de produção de café no Sul de Minas Gerais ...................................... 36

5 Variáveis relacionadas à tecnologia de produção e clima ................................... 50

6 Variáveis relacionadas com o retorno financeiro do investimento ........................ 51 


\section{LISTA DE TABELAS}

Página

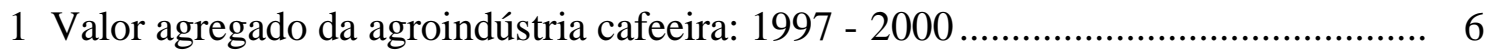

2 Caracterização dos sistemas de produção de café ................................................. 7

3 Modelo de maximização do valor esperado: principais resultados

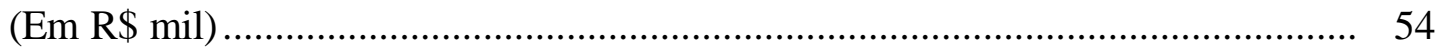

4 Análise de sensibilidade no modelo de maximização da utilidade

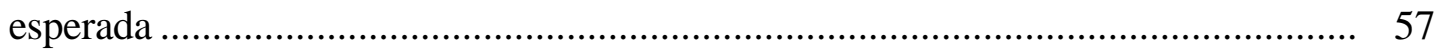




\title{
AVALIAÇÃO DE SISTEMAS DE PRODUÇÃO DE CAFÉ NA REGIÃO SUL DE MINAS GERAIS: UM MODELO DE ANÁLISE DE DECISÃO
}

\author{
Autor: GLAUCO RODRIGUES CARVALHO \\ Orientador: Prof. FERNANDO CURI PERES
}

\section{RESUMO}

O café é um dos mais tradicionais produtos da agricultura brasileira e teve grande influência no processo de industrialização da economia. É também um produto que contribui significativamente para a geração de emprego no campo, principalmente em regiões inaptas à mecanização da lavoura. A cafeicultura passou por uma significativa reestruturação nas últimas décadas, que modificou tanto a organização interna entre os elos da cadeia agroindustrial, como as práticas de condução das lavouras pelo produtor rural. Sistemas alternativos de produção foram surgindo com o objetivo de aumentar a competitividade dessa lavoura. Na esteira desses sistemas, emergem dúvidas quanto à viabilidade técnica e econômica de cada um. Esse trabalho está dividido em duas partes. Primeiramente procurou-se identificar as técnicas de produção que estão sendo adotadas e caracterizar as dúvidas existentes. Em seguida, partiu-se para a elaboração de um modelo fundamentado nas técnicas de análise de decisão, para auxiliar nas escolha entre alternativos sistemas de processamento de café, na forma tradicional ou especial, uma das dúvidas que foram identificadas. As decisões disponíveis indicavam a possibilidade de produzir um café natural (no sistema tradicional vigente ou 
mais elaborado), um café cereja descascado ou um café despolpado. Essas alternativas, por sua vez, envolvem investimentos e são expostas a condições de risco, já que o clima pode influenciar os resultados da lavoura e a qualidade do grão. Por meio dessa pesquisa foi possível identificar, entre outros resultados, uma ligeira distorção entre as demandas dos produtores e os estudos de especialistas que, em muitos casos, dão excessiva importância a aspectos considerados triviais para os cafeicultores. Além disso, a pesquisa proporcionou avaliar os sistemas de processamento do café e identificar os cafés especiais como uma boa alternativa aos produtores do Sul de Minas Gerais. 


\title{
VALUATION THE COFFEE PRODUCTION SYSTEMS IN THE SOUTHERN MINAS GERAIS: A DECISION MODEL ANALISYS
}

\author{
Author: GLAUCO RODRIGUES CARVALHO \\ Adviser: Prof. FERNANDO CURI PERES
}

\section{SUMMARY}

Coffee is one of the most traditional products of the Brazilian agriculture and had a great influence on the industrialization process of economics. It is also a product which contributes significantly for generation of employment in the field mainly in the regions unsuitable for mechanization of farming. Coffee growing has past by a significant restructuration in the last few decades which has changed both the internal organization among the links of the agribusiness chain and the practices of conducting crops at the farmer's level. Alternative systems of farming have been appearing with the purpose of increasing the competitiveness of those crops. On the track of those system appears the doubts as to the economical and technical viability of each one. This work was divided into two parts, where first its was sought to identify the cropping techniques which have been being adopted and to characterize the existing doubts. Next, the making of a working model was started in the decision -analysis techniques to aid in the choice among alternative coffee -processing systems either in the traditional or special form, one of the doubts which were identified. The available decisions point out the possibility of producing a natural coffee (in the current traditional or more elaborated), either a pulped naturals or washed coffee. Those alternative, in turn, involve investments and are 
exposed to risk conditions since the climate may influence the results of the crop and bean quality. By mean of the research work, it was possible to identify among other results, a slight distortion among the demands of the farmers and the studies by experts, which in a lot of cases give an excessive importance to aspects regarded as trivial to the coffee growers. In addition, research has proposed to evaluate the coffee- processing systems and to identify the special coffees as a good alternative to the farmers of Southern Minas Gerais. 


\section{INTRODUÇÃO}

A agricultura é um setor que apresenta forte franja concorrencial, em função do grande número de produtores, da disponibilidade de tecnologias e das baixas barreiras à entrada e saída. Outro aspecto importante dessa atividade é a exposição ao risco, uma vez que seus resultados são influenciados diretamente por variáveis climáticas.

O café é um dos mais tradicionais produtos da agricultura brasileira, tendo as primeiras lavouras sido formadas há quase 200 anos. Ao longo desse período muitas mudanças aconteceram em termos de localização da lavoura, tecnologias de produção (formação e manejo) e métodos diversos de colheita e pós-colheita.

O setor vivenciou, nas últimas décadas, mudanças significativas na geografia da produção, redução do papel do governo e adoção de novas tecnologias. $\mathrm{Na}$ distribuição geográfica, os estados do Paraná e São Paulo perderam participação na produção nacional, vis a vis o incremento em Minas Gerais e Espírito Santo.

Em relação a políticas setoriais, destaca-se o fim do IBC (Instituto Brasileiro do Café), em 1989, que exercia o papel de maior gestor de políticas cafeeiras e comprador do produto. Isso levou a uma necessidade de rever as inter-relações na cadeia produtiva, já que os compradores atuais são representados por consumidores exigentes tanto no mercado interno como externo. Vale ressaltar também o fim dos Acordos Internacionais do Café (AIC) - apesar da desastrosa experiência recente com o plano de 
retenção -, que influenciavam os preços do produto via controle da oferta mundial dessa rubiácea ${ }^{1}$.

Adicionando-se as mudanças geográficas e políticas, verificou-se no setor a utilização de sistemas de produção inovadores, buscando aumento da competitividade por meio da diferenciação de mercado pela qualidade, redução de custos via elevação de produtividade e adoção de novas tecnologias de produção pré e pós colheita (Martin et al., 1995; Grossi, 1998).

O adensamento da cultura é uma dessas inovações tecnológicas, em que se eleva o número de plantas por hectare, conseguindo maior produção com a mesma unidade de área. Há também um crescente uso de máquinas para o manejo da lavoura, técnicas de irrigação e desenvolvimento de novas variedades de cultivar. Por fim, podese incluir a adoção de sistemas de produção baseados na melhoria da qualidade do produto, que possibilita atender segmentos do mercado que demandam produtos diferenciados. Esse é o caso, por exemplo, da produção de café orgânico e cafés especiais ("gourmets").

Em decorrência dessas transformações recentes do setor cafeeiro existe uma demanda por pesquisa sobre sistemas de produção mais apropriados às realidades regionais e que atendam aos anseios do mercado consumidor.

Até pouco mais de uma década, o cenário da cafeicultura tinha o governo como forte agente interventor, absorvendo grande parte dos riscos percebidos pelo setor. Nos sistemas de produção, não havia uma preocupação com a qualidade do produto, uma vez que essa não era reconhecida. Em virtude disso, o que se verificava era a necessidade de produzir sem a preocupação ex-post de atender demanda, refletindo, se assim pode-se dizer, em um papel limitado do setor privado e uma conjuntura sem muitas decisões complexas para serem avaliadas.

\footnotetext{
${ }^{1}$ Para uma revisão histórica dos acordos internacionais, ver Moricochi et al. (1994).
} 
O ambiente atual, no entanto, aumentou a importância das decisões privadas. Isso porque os sistemas de produção tornaram-se mais complexos e existe a necessidade de produzir café de boa qualidade a preços competitivos. Portanto, a responsabilidade individual na tomada de decisão ganha uma dimensão maior.

Diante dessas mudanças estruturais da cafeicultura, são numerosas as propostas de sistemas de produção inovadores que buscam aumento da competitividade via qualidade, custos, automação, entre outras tecnologias. Como essas propostas envolvem investimentos e alterações nas práticas tradicionalmente utilizadas, é natural que existam dúvidas quanto ao seu mérito técnico e econômico, quando consideradas as características peculiares de uma dada região produtora. A importância desse estudo relaciona-se ao fato de procurar caracterizar as idéias dos produtores e, a partir daí, construir um modelo de decisão para auxiliá-los no processo de escolha dos sistemas de produção disponíveis.

\subsection{Objetivos}

\subsubsection{Objetivo geral}

O objetivo geral deste estudo é levantar questões de dúvida entre produtores de café e construir um modelo, embasado na teoria e técnicas de análise de decisão, que possa auxiliar os cafeicultores na escolha entre alternativos sistemas de produção. Espera-se, assim, contribuir para o aumento da eficiência técnica e econômica do setor, bem como auxiliar no entendimento das consequiências dos diferentes sistemas. Por ser um instrumento útil na análise de projetos de investimento no âmbito privado, espera-se também que o modelo auxilie na realização de novos estudos e no desenvolvimento de alternativas de produção de café que, eventualmente, não estejam sendo adotadas. $\mathrm{O}$ enfoque do estudo foi voltado para variáveis técnicas e procurou-se trabalhar com sistemas encontrados na região sul de Minas Gerais. 


\subsubsection{Objetivos específicos}

1) Levantar e caracterizar sistemas alternativos de produção de café na região sul de Minas Gerais.

2) Levantar e caracterizar dúvidas, junto a produtores, dentro dos sistemas encontrados.

3) Levantar dados técnicos e econômicos dos sistemas que apresentaram maior dúvida.

4) Modelar as consequiências econômicas desses sistemas.

5) Comparar os méritos relativos de cada sistema por meio das técnicas associadas à análise de decisão (valor esperado e utilidade esperada).

\subsection{Estrutura do trabalho}

O trabalho está formalizado em quatro partes, além desta inicial (capítulo 1). $\mathrm{Na}$ primeira parte, segundo capítulo, apresenta-se uma breve revisão de alguns trabalhos voltados para sistemas de produção de café, comentando, em seguida, sobre a técnica qualitativa de pesquisa. Continuando nesse capítulo, faz-se uma descrição geral sobre a teoria de decisão e apresentam-se alguns estudos que a utilizaram. Finalmente, apresenta-se a ferramenta computacional utilizada na construção do modelo de decisão, ou seja, o diagrama de decisão.

No terceiro capítulo encontra-se o primeiro artigo do estudo. Este artigo, tem por objetivo principal levantar questões onde existem dúvidas sobre a produção de café do ponto de vista dos produtores, possibilitando, em seguida, caracterizar alternativos sistemas de produção na região do estudo. Este capítulo procura atender aos dois primeiros objetivos específicos. Utiliza-se, como ferramenta metodológica, a técnica de pesquisa qualitativa Grupo Focal (ou Focus Group), realizada junto a produtores e agrônomos no pólo cafeeiro da região sul de Minas Gerais.

O quarto capítulo é destinado à apresentação do segundo artigo, no qual ocorre a formalização e modelagem dos sistemas encontrados, atendendo, assim, o 
restante dos objetivos específicos. Nele, descreve-se todo o modelo, aspectos gerais da teoria da decisão e procedimentos metodológicos. Em seguida, os principais resultados são analisados e discutidos.

O quinto capítulo é destinado às conclusões gerais do estudo, seguido pelas referências bibliográficas.

\subsection{A importância do café no Brasil}

O café é uma importante commodity no mercado mundial de produtos agrícolas e agroindustriais. Estima-se que o agronegócio café movimente cerca de US\$55 bilhões anuais em todo o mundo (Strenger, 2001).

No Brasil, é um exemplo de produto que prosperou sobre os objetivos de desenvolvimento econômico, cuja importância transcendia em muito os limites das políticas setoriais. O café foi, por muito tempo, a única fonte de divisas para financiar o processo de industrialização pelo qual passou a economia brasileira no último século.

A política do café foi manejada como instrumento para industrialização, transferindo recursos do setor agrícola, então grandemente baseado no café, para os setores industriais urbanos emergentes. A curto prazo, fazia sentido arrecadar o máximo de dólares por saca exportada para viabilizar, a longo prazo, o setor escolhido como motor do desenvolvimento, isto é, o setor industrial (Ferreira Filho, 1993; Bacha, 1992).

Em termos sociais, a atividade de produção cafeeira é grande geradora de empregos e fixadora de mão-de-obra no campo. Estima-se que ela empregue cerca de 4 milhões de pessoas na produção. Considerando todos os segmentos envolvidos (produção, indústria, comércio e serviços), o número de empregos pode chegar a 10 milhões (Cenário, 1995).

Em termos econômicos, o valor adicionado do sistema agroindustrial do café no Brasil, em 1997, foi de US\$ 6,4 bilhões, reduzindo para US\$ 4,2 bilhões em 2000 
(Tabela 1). Essa redução, em 2000, pode ser atribuída ao fraco desempenho das exportações e às baixas cotações do produto.

Tabela 1. Valor agregado da agroindústria cafeeira: 1997 - 2000.

\begin{tabular}{lrrrr}
\hline \multicolumn{1}{c}{ Indicador } & 1997 & 1998 & 1999 & 2000 \\
\hline $\begin{array}{l}\text { Produção Industrial* - (a) } \\
\text { (milhões de kg) }\end{array}$ & 552 & 586 & 610 & 624 \\
Preço café** - (b) & 6.1 & 5.3 & 3.4 & 3.9 \\
(US\$/kg) & & & & \\
& & & & \\
Exportação (verde e solúvel) - (c) & $3,095.0$ & $2,596.0$ & $2,444.0$ & $1,775.0$ \\
(em milhões de dólares) & & & & \\
& & & & \\
Valor agregado - [(a) x (b)] + (c) & $6,452.0$ & $5,693.0$ & $4,524.0$ & $4,238.0$ \\
(em milhões de dólares) & & & & \\
\hline
\end{tabular}

Fonte: Elaboração do autor, a partir de dados do Coffee Business, ABIC, Febec, Decex. *Consumo menos $20 \%$ de perda na industrialização.

**Preço médio dos produtos (Coffee Business) convertido pelo dólar médio do ano.

No cenário internacional, o Brasil sempre ocupou a posição de maior produtor e exportador mundial de café, apesar de apresentar, historicamente, queda de participação. Diante dos números do agronegócio café no Brasil e no mundo, e da mudança de cenário nos diversos segmentos da cadeia, os próximos capítulos são destinados ao estudo da produção dessa rubiácea. 


\section{REVISÃO DA LITERATURA}

\subsection{Sistemas de produção de café}

A caracterização de um sistema de produção envolve tecnologias que vão desde uso mais simples e rotineiro, até as mais sofisticadas técnicas na condução da lavoura. Na Tabela 2, descrevem-se algumas possíveis formas de produção de café.

Tabela 2. Caracterização dos sistemas de produção de café.

\begin{tabular}{ll}
\hline \multicolumn{1}{c}{ Variáveis } & \multicolumn{1}{c}{ Tecnologias } \\
\hline Espaçamento & $\begin{array}{l}\text { Super-adensado; adensado; semi-adensado; renque- } \\
\text { mecanizado; tradicional. }\end{array}$ \\
Manejo dos tratos & Manual; tração animal; mecanizado. \\
Condução das plantas & Aberto; periodicamente aberto ou com podas; \\
Condição climática & sempre fechado. \\
Trato nutricional & A pleno sol; arborizado ou sombreado; irrigado. \\
& Rotineiro (sem adubação); químico ou combinação \\
Sistema de controle fitossanitário & Rotineiro (sem controle); controle natural (genético \\
& ou inimigos naturais); via pulverização; via solo. \\
\hline
\end{tabular}

Fonte: Matiello (1995) 
Um sistema de produção é configurado pela combinação no uso ou na forma de adotar as tecnologias aqui agrupadas. Muitos estudos foram elaborados ao longo dos últimos anos, voltados para a cafeicultura. Dentre os diversos assuntos tratados, o espaçamento da lavoura foi sempre motivo de debates. Isso levou ao desenvolvimento de uma infinidade de trabalhos sobre o tema.

A escolha da densidade de plantio de café é uma variável de estrema importância para o sucesso e retorno da lavoura, pois ela irá determinar os tratos culturais necessários e as possíveis tecnologias a serem empregadas. Segundo Miguel, et al. (1986) além da produtividade, ao se recomendar um espaçamento, deve-se levar em consideração uma série de fatores. Entre eles: mecanização de tratos culturais, mecanização da colheita, riscos climáticos, condições topográficas, condições climáticas e seus reflexos na maturação, escolha do cultivar (variedade), alternativas agrícolas existentes, disponibilidade de mão-de-obra, tamanho da propriedade, condução da cultura (adoção de podas) e custo inicial de formação. Para completar esse quadro, Matiello (1995) acrescenta a área disponível para o café e a capacidade técnica e financeira do produtor.

Nos principais países produtores de café, o espaçamento evoluiu no sentido de aumentar a população de plantas por unidade de área. A consequiência direta foi uma elevação da produtividade das lavouras, em sacas por hectare (Bartholo et al., 1998).

Bartholo et al. (1998) fazem um grande histórico dos espaçamentos no Brasil. Esses autores mostram que, no período anterior a 1.900, eram encontrados cafeeiros dispostos em quadrados de 4,48 a 5,28 m, outros de 2,64 a 3,08, chegando a se plantar 10 mudas por cova, formando espécies de "moitas".

Ensaios foram realizados pelo Instituto Agronômico de Campinas (IAC), no período de 1936 a 57, utilizando espaçamentos de 3,5 m entre as fileiras e no outro sentido (no interior da fileira), distâncias se reduzindo de $3,7 \mathrm{~m}$, seguido por 3,5 m, 3,3 $\mathrm{m}$ e assim por diante. Para todos os espaçamentos existiam blocos com uma, duas, três e 
quatro plantas por cova. Os resultados mostraram uma tendência de redução da produção por cova, quando diminuiu-se o espaçamento, havendo, porém, um aumento considerável da produção por área (Bartholo et al., 1998).

A partir de 1980, outros inúmeros ensaios foram realizados (principalmente por técnicos do IBC) e mostraram grande vantagem do plantio com menor distância entre covas, na mesma linha. Assim, de 1,5 a 2,0 m, houve evolução para 0,5 a 1,0 m (Matiello, 1995). Isso levou a um predomínio dos plantios em renque, com 3,5 a 4,5 m x 0,5 a 1,0 m e uma planta por cova, na esteira dos receituários agronômicos. Desde essa data, evidenciou-se também o plantio adensado, com uma população de 5.000 a 10.000 plantas/ha. Em seguida, surgiu o super-adensamento, com mais de 20.000 plantas/ha.

Com o objetivo de avaliar as produtividades de quatro cultivares de café (Catuaí Amarelo, Mundo Novo, Acaiá e Icatu), Siqueira et al. (1990) conduziram um experimento em Londrina,PR, no período 1977 a 1990, onde estudaram as seguintes densidades: 1,$4 ; 2,8 ; 4,2 ; 5,6 ; 7,0 ; 8,4 ; 9,8$ e $11,2 \mathrm{~m}^{2} /$ cova, cada cova com duas plantas. $\mathrm{Na}$ média de 11 colheitas (1979-89), as maiores produtividades das cultivares Catuaí, Mundo Novo e Acaiá foram obtidas na densidade 2,8 $\mathrm{m}^{2} /$ cova $(2,5 \times 1,12 \mathrm{~m})$. A variedade Icatu foi a apresentou maior resposta ao adensamento, obtendo produtividade mais alta, na densidade $1,4 \mathrm{~m}^{2} /$ cova. Para as demais, observou-se que densidades superiores a $2,8 \mathrm{~m}^{2} /$ cova reduziam a produtividade média.

Toledo et al. (1992) realizaram um trabalho com evidência de 8 colheitas, procurando analisar o efeito do espaçamento entre linhas, com quatro diferentes situações, ou seja, $4 \mathrm{~m}$ entre as linhas e, na linha, $0,5 \mathrm{~m}, 1 \mathrm{~m}, 1,5 \mathrm{~m}$ e $2 \mathrm{~m}$ para a cultivar Mundo Novo. O ensaio foi conduzido em Varginha, MG e concluiu-se que o melhor espaçamento entre plantas foi de $1 \mathrm{~m}$, utilizando uma planta/cova. Comparando-o ao espaçamento $4 \times 2 \mathrm{~m}$, encontrou-se, para a primeira colheita, uma produtividade $77 \%$ superior e para a média das oito colheitas, 19\% superior. Concluíram também que a variedade Mundo Novo não é indicada para plantio com menos de $1 \mathrm{~m}$ entre plantas na linha. 
Pádua (1998) estimou funções de produção para diversos espaçamentos entre plantas e entre fileiras, decidindo-se pelo experimento com maior receita líquida. $\mathrm{O}$ espaçamento ótimo foi obtido na distância 3,00 x 0,75 m. Contudo, quando se incluía a hipótese de mecanização da lavoura, o espaçamento de 3,00 x 0,50 m foi superior.

Em outro bom trabalho, Nacif (1997) estudou o comportamento do adensamento da lavoura, porém, com enfoque um pouco diferente dos trabalhos usuais (o efeito do adensamento sobre a produção e a produtividade). Ele procurou avaliar a influência de diferentes densidades populacionais e dose de adubo sobre o desenvolvimento vegetativo e reprodutivo da planta. As distribuições espaciais de 1,50 x $1,00 \mathrm{~m}$ e de $3,00 \times 0,50 \mathrm{~m}$, ambas com 6.666 plantas por hectare, apresentaram resultados mais satisfatórios, tanto no aspecto vegetativo quanto em termos de receita por área e custo unitário de produção.

Segundo Matiello (1995), no Brasil, onde a mecanização é possível em grande parte das áreas cafeeiras, o adensamento é uma boa opção. Não obstante, devem permanecer, de forma bem significativa, os sistemas abertos nas ruas (renque), que privilegiam o uso de máquinas. Isso principalmente nas grandes plantações e nas regiões carentes de mão-de-obra, ou onde e quando seu custo for muito elevado.

Em algumas regiões produtoras, como o cerrado mineiro e o oeste baiano, por exemplo, o uso mais intensivo de máquinas é uma realidade, o que viabiliza a produção em grande escala. A utilização de máquinas na colheita tem possibilitado uma melhoria da competitividade da produção cafeeira, pois apresenta custo inferior ao sistema manual. Kashima et al. (1986) realizaram um trabalho no município de Patrocínio- MG sobre a viabilidade da colheita mecânica, observando seu impacto sobre a planta. Comparada à colheita manual, concluiu-se que a colheita mecânica não apresentou resultados prejudiciais significativos às plantas, nem influenciou na eficiência e rendimento da colheita. O mesmo resultado foi obtido por Faya et al. (1979).

Grossi (1996), analisando a viabilidade da cafeicultura empresarial, extensiva, fez uma avaliação do custo da colheita, manualmente e mecanizada, com 
máquina própria e alugada, na região de Patrocínio, MG. A colheita manual foi considerada a mais onerosa, seguida pela que utilizou máquina alugada e por último, apresentando menor custo, com máquina própria. A economia em relação à colheita manual chegou a $26 \%$ e 39\% para as máquinas alugada e própria, respectivamente.

Atualmente, vêm merecendo destaque, estudos voltados para a qualidade do café e sistemas de processamento pós-colheita. A maioria dos trabalhos desenvolvidos se apoiaram, fundamentalmente, em questões técnicas, buscando informações sobre: as diferentes maneiras de preparar o café, os fatores que afetam sua qualidade, as características químicas do fruto nos diversos níveis de maturação, entre outros aspectos.

Bartholo e Guimarães (1997), realizaram descrição das etapas de colheita e preparo do café, destacando possíveis impactos sobre a qualidade. Foram mostradas as alternativas tecnologias de colheita, processamento, secagem, armazenagem e métodos de beneficio e rebenefício do café, buscando eliminação de defeitos que influenciam negativamente na qualidade da bebida.

Carvalho et al. (1997b) e Carvalho (1997c) procuram avaliar a qualidade do café a partir dos cuidados pré e pós-colheita. Foram analisados os fatores que afetam a qualidade e a composição química dos grãos, destacando os efeitos da chuva na fase de preparo, a presença de defeitos e a qualidade da bebida. Foi considerado ainda, o impacto dos diferentes níveis de maturação do fruto na qualidade. Nesse último aspecto, o café no estágio de maturação cereja apresentou qualidade superior aos demais. Por fim, Garruti \& Gomes (1961), in. Carvalho (1997c), concluíram que a qualidade do café cereja despolpado também é superior ao não despolpado.

Segundo Bartholo e Guimarães (1989), o café brasileiro tem seu preço vinculado a parâmetros qualitativos, variando com o preparo do produto. As perdas de preço (ou deságio) irão oscilar em função dos aspectos visuais do grão (cor, peneira, tipo) e da qualidade da bebida. 
O crescimento da demanda pelos chamados cafés gourmets tem alterado o comportamento de alguns cafeicultores no Brasil, na busca de nicho de mercado. O consumo de cafés especiais vem crescendo assustadoramente nos últimos anos, liderado pelos EUA e Japão. Segundo Mello (2001), nos Estados Unidos, os cafés especiais já representam cerca de $16 \%$ do consumo total, com vendas anuais superiores a US\$ 17 bilhões.

Enquanto o consumo mundial do café tradicional cresce em ritmo lento, de 1,5\% ao ano, a dos cafés especiais dispara. Na década de 1990, as vendas desse tipo de café subiram, em média, $9 \%$ ao ano. No mercado norte-americano, $51 \%$ da população com idade acima de dez anos declaram-se, em 1999, consumidores de café "gourmet". Em 1998, esse percentual era de 47\% e em 1997, 35\% (Associação Nacional do Café, Apud Mello (2001)). Em função desse crescimento de consumo, detecta-se um grande nicho de mercado a ser explorado pelos cafeicultores brasileiros, não apenas olhando para o mercado internacional mas, sobretudo, para alavancar o consumo doméstico.

\subsection{Pesquisa qualitativa ${ }^{2}$}

A utilização de pesquisa qualitativa ou de um estudo exploratório apresentase como um poderoso instrumento para levantamento de demanda de pesquisa ou para outros fins de investigação. Segundo Ruiz (1982), o objetivo de uma pesquisa exploratória é a caracterização inicial do problema e sua apropriada formalização. É, portanto, o primeiro estágio da pesquisa científica, não tendo por objetivo resolver de imediato o problema, mas tão somente apanhá-lo, caracterizá-lo.

Para estudos que envolvem análise de decisão, autores consagrados na área (Hammond et al. 1998a, 1998b) enfatizam a importância de um entendimento adequado do problema, eventualmente, a partir da utilização de técnicas formais que possam

${ }^{2}$ Este subitem e os próximos do capítulo de revisão da literatura serão descritos de forma bastante resumida, já que nos artigos dos capítulos 3 e 4 constam uma revisão sobre os temas. Optou-se por penalizar o capítulo específico da revisão de literatura vis a vis o conteúdo dos artigos, evitando duplicidade para o leitor. 
propiciar esse melhor entendimento, de forma a prevenir esforços na busca de resolução de problemas errados.

O grupo focal é uma técnica de cunho qualitativo para coleta de dados. Pode ser considerado como um tipo de entrevista em grupo, porém, de forma diferente da entrevista padrão, onde se alternam as perguntas do entrevistador e as respostas do entrevistado. Essa técnica utiliza sessões grupais e tem como essência a interação de opiniões entre os participantes para colher dados, a partir de temas que são fornecidos pelo moderador do grupo. Segundo Carlini-Cotrim (1996), a utilização deste método foi proposta primeiro pelo cientista social Robert Merton, na década de 1950. Atualmente, pesquisadores da área de marketing usam esse instrumento com grande freqüência.

As sessões grupais como técnica de pesquisa são recomendadas pela maior possibilidade que oferecem para se pensar coletivamente sobre um determinado assunto, de interesse e conhecimento de todos ali presentes. Além disso, muitas vezes os comentários de certos indivíduos fazem emergir a opinião de outros. A coleta de dados por meio de grupo focal tem, como uma de suas maiores riquezas, a vantagem de basearse na tendência humana de formar opiniões e atitudes na interação com outros indivíduos.

Alguns usuários da técnica grupo focal argumentam que uma de suas maiores vantagens está na possibilidade de se atingir maior número de pessoas ao mesmo tempo, a um custo relativamente baixo e com grande velocidade no fornecimento de dados qualitativos relevantes [Westphal et al. (1996), Carlini-Cotrim (1996)].

Além do emprego geral do grupo focal, sua utilização pode ser feita internamente nas empresas, para definição de estratégias e planejamento, avaliação de propostas de trabalho, políticas salariais, pesquisa de consumo, avaliação de performance administrativa, entre outros fins [Bader \& Rossi (1999)]. Mais informações sobre esse tema podem ser encontradas no capítulo 3. 


\subsection{Teoria de decisão}

\subsubsection{O processo de implementação de análise e engenharia de decisão}

No capítulo 4 é apresentada uma metodologia geral desenvolvida por Azevedo Filho $(2000)^{3}$, para a análise de decisão. Em sua representação, as bases para o processo de análise e engenharia de decisões consistem, na teoria de probabilidade, nos axiomas da teoria de decisão e na clareza na representação e comunicação entre os agentes.

O início do processo de engenharia de decisão ocorre no entendimento apropriado do problema para, a partir daí, tirar conclusões corretas sobre o estudo em questão. É necessário bastante rigor para a determinação do problema, procurando evitar esforços na busca de "solução ótima para o problema errado" ou mesmo irrelevante (Hammond et al., 1998a, 1998b).

Definido o problema, o levantamento das alternativas, consequiências e preferências é desenvolvido num processo iterativo entre o analista, especialista, tomador de decisão e evidências da literatura, no que se define como origem do conhecimento.

O objetivo principal de um modelo de análise de decisão consiste na ligação entre dois extremos ou estados: um estado inicial, onde há dúvida sobre a æ̧̧ão/decisão apropriada (situação obscura) e o estado final, onde se tem certeza sobre a ação/decisão a ser tomada (situação clara). No processo de modelagem há uma iteração constante entre os agentes envolvidos, recorrendo a sucessivos refinamentos até que o modelo responda, coerentemente, à realidade em análise (ver Figura 2, no capítulo 4).

\footnotetext{
${ }^{3}$ AZEVEDO FILHO, A.J.B.V. Análise de decisões e administração de riscos. Notas de aula, 2000.
} 


\subsubsection{Modelos de maximização do valor esperado}

Modelo de maximização do valor esperado implica que, se o tomador de decisão se defronta com duas decisões $D_{X}$ e $D_{Y}$ com valor esperado $E\left(D_{X}\right)$ e $E\left(D_{Y}\right)$, respectivamente, a melhor decisão ou estratégia a seguir é a que retorna o maior valor esperado, $\mathrm{E}($.$) .$

\subsubsection{Modelos de maximização da utilidade esperada}

A maximização do valor esperado tem um significado particular em economia, pois, um indivíduo que se comporte como tal, seria classificado como neutro em relação ao risco (Friedman \& Savage, 1948). Este não é, contudo, um comportamento esperado para os agricultores, ou para qualquer tipo de empresário. Normalmente, os indivíduos são "avessos" ao risco (Peres, 1990).

Considerando que a decisão do agricultor é estritamente pessoal, e tendo em vista os riscos que ele percebe freqüentemente, é fácil reconhecer que ele tenha objetivos bem diversos daquele indivíduo, unicamente, maximizador da renda. Vários estudos comprovam que o agricultor não busca esta maximização da renda em primeiro plano, mas, sim, baseia suas decisões em critérios de maximização da utilidade esperada (Salomão, 1990; Garcia \& Cruz, 1979; Pacheco, 1985). Esta pode ser entendida, usando a definição de Garcia \& Cruz (1979), como sendo a ênfase que o agricultor dá aos critérios econômicos e psicológicos, que estabelecem suas preferências com respeito à renda e ao risco.

Naturalmente, existe, para cada indivíduo, um mapa de utilidade, refletindo a subjetividade dos critérios de decisão. Os problemas de escolha em condições de incerteza têm sido, tradicionalmente, tratados no contexto de maximização de uma função de utilidade esperada. Portanto, se a preferência do indivíduo é compatível com os axiomas da teoria de decisão, pode-se construir um mapa de utilidade, tal que permita a ordenação das escolhas do indivíduo (Yarri, 1969). 
O modelo utilizado é fundamentado no pressuposto de que o agente econômico deseja definir suas ações, de forma a maximizar a esperança matemática da função utilidade. Ou seja, se o agente encontra pela frente a necessidade de escolher entre ações alternativas pertencentes ao conjunto

$$
\Omega_{a} \equiv\left\{a_{1}, a_{2}, \ldots, a_{n}\right\}
$$

com a consequiência da ação $\mathrm{a}_{\mathrm{i}}$ sendo $W\left(a_{i}\right)$ uma proxy da riqueza incerta do agente, definida por uma variável aleatória condicionada por $a_{i}$. Nesse contexto, o agente optará pela ação ótima $a^{*} \in \Omega_{a}$, definida por

$$
a^{*}=\max _{a \in \Omega_{a}} \mathrm{E}(u(W(a)))
$$

ou, para simplificar a notação,

$$
a^{*}=\max _{a \in \Omega_{a}} \operatorname{E} U(W(a))
$$

ou seja, a ação que maximiza a esperança da utilidade desse agente. Na eq. (2) a função utilidade considerada é do tipo VN-M (Von Neumann-Morgenstern). Ela representa as preferências de um agente que aceita os axiomas da teoria da decisão, o que acarreta a seleção de alternativas pelo critério da esperança matemática da utilidade, representada diretamente pelo operador EU na eq. (3) (Azevedo Filho, 2001).

A função de utilidade representada pela exponencial negativa é uma função que se aproxima bastante das análises de utilidade aplicadas à agricultura, (Anderson et al, (1977)), sendo descrita conforme a eq. (4), em que W representa a riqueza do agente e r o coeficiente de aversão absoluta ao risco.

$$
u(W)=-e^{-r W}
$$

O coeficiente de aversão ao risco também pode ser representado na forma relativa, aqui representado por $R$ e, usualmente, definido por: 


$$
R=r w_{0}
$$

Em que $w_{0}$ representa uma proxy para a riqueza do indivíduo. Neste caso, a função exponencial negativa seria representada por:

$$
u(W)=-e^{-R \frac{w}{w_{0}}}
$$

O uso do coeficiente de aversão ao risco relativo é conveniente pelo fato de existir alguma evidência empírica sobre a magnitude do valor de $R$ no mundo real. Alguns autores argumentam que valores realistas para $R$ estão entre 0 e 10 , mais comumente no intervalo entre 0,5 e 6 , em que 0 representa a situação na qual não há aversão ao risco e 10, uma aversão ao risco extrema. Para argumentos suportando essa colocação sobre os valores razoáveis para R, veja Markovitz, Reid e Tew (1994) e Lence (1995), citados por Azevedo Filho (2001).

Azevedo Filho (2001) apresenta um experimento simples, que facilita o entendimento do significado prático desses valores. Agentes são perguntados sobre o valor crítico de probabilidades $p$ que tornaria equivalente as seguintes alternativas: (a) permanecer com sua riqueza atual wo; e, (b) aceitar participar de um jogo, cujo resultado será definido por um sorteio, onde o agente receberá duas vezes sua riqueza, ou seja $2 \mathrm{w}_{0}$, com probabilidade $p$ e metade de sua riqueza, ou seja, 0,5 $\mathrm{w}_{0}$, com probabilidade $(1-p)$.

O Gráfico 1 mostra a relação entre os valores de $\mathrm{p}$ informados e valores de $\mathrm{R}$ implícitos na escolha. Esses valores foram obtidos pela solução numérica do problema de se encontrar o valor de R que iguala a esperança da utilidade nas situações (a) e (b), descritas no parágrafo anterior, considerando a eq. (6). 


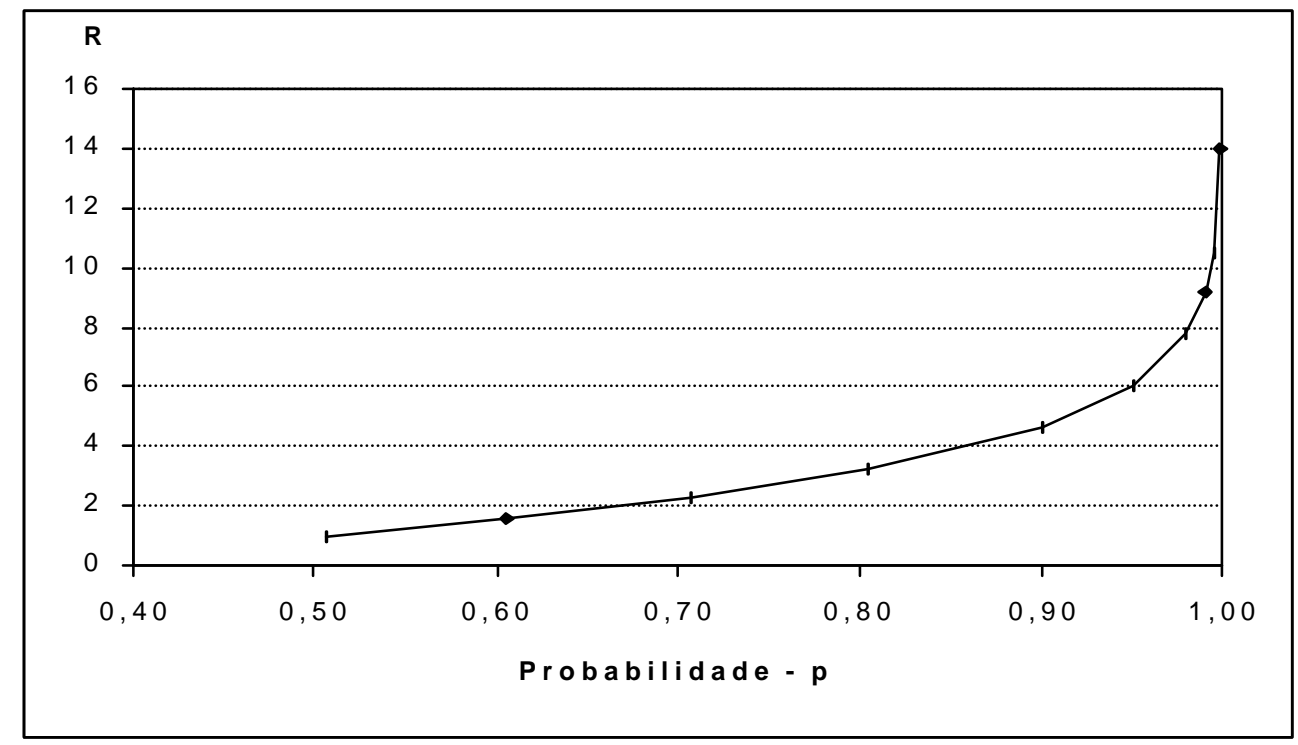

Gráfico 1 - Coeficiente de aversão relativo ao risco e valores de $p$.

Fonte: Elaboração do autor

\subsubsection{Diagramas de decisão}

Para complementar ao uso de árvores de decisão, um instrumental que vem sendo bastante utilizado, é utilizado o diagrama de decisão ou diagrama de influência. Esse diagrama foi desenvolvido, originalmente, por R. Howard (Howard \& Matheson (1984), Howard (1990)) e formalizado por R. Shachter (1986, 1987). É um instrumento conveniente para representação de problemas complexos de decisão, por meio de uma linguagem gráfica, relativamente inteligível por pessoas envolvidas com o problema sem grande treinamento em métodos quantitativos.

O diagrama pode ser utilizado em diferentes etapas no processo de análise da decisão, seja na fase inicial (ferramenta para análise qualitativa) ou na fase final (análise quantitativa). Essa fase, usualmente, envolve a especificação das preferências e indicadores utilizados para avaliação dos méritos das alternativas (em muitos casos esse indicador será a esperança matemática da utilidade). 
Todo diagrama de decisão, totalmente especificado, espelha uma distribuição conjunta de probabilidade. A estrutura do problema fica facilmente disponível para observação e manipulação, o que acaba tornando esse instrumento conveniente para a representação em interfaces gráficas de programas desenvolvidos para apoio à análise de decisão. O diagrama de decisão utiliza elementos gráficos, como círculos, quadrados, hexágonos e setas (ver Figura 3, no capítulo 4).

Na construção do modelo utilizando diagrama de decisão, define-se primeiro quais as variáveis relevantes ao problema estudado. Para cada variável atribuem-se diferentes estados que elas podem assumir. Assim, diferentes resultados de um evento aleatório são distintos estados da natureza (Hillier et al, 1988). Caso seja uma variável de decisão, definem-se as possíveis escolhas do tomador de decisão.

Feito isso, o próximo passo consiste no entendimento da relação entre as variáveis, procurando identificar quais condicionam ou são condicionadas pelas demais. Dessa forma, se a variável $\mathrm{X}$ influencia a variável $\mathrm{Y}$, unem-se ambas por uma seta de condicionamento, no sentido de $\mathrm{X}$ para $\mathrm{Y}$. Este processo deve ser feito para todas as variáveis envolvidas no problema.

Em seguida, atribuem-se probabilidades à ocorrência dos distintos estados da natureza, se condicionados ou não. Se a variável assume algum valor específico (custo de um investimento, por exemplo) então, o modelo deve ser devidamente "alimentado" com o valor que representa o custo daquela decisão específica.

Na construção da função objetivo são utilizados indicadores para avaliação do mérito das alternativas (neste estudo foram utilizadas maximização valor esperado e utilidade esperada). Esta função irá definir qual a melhor decisão para o agente.

\subsubsection{Algumas aplicações da teria de decisão}

Por ser um setor altamente competitivo, alguns trabalhos na área agrícola vêm sendo realizados para auxiliar no planejamento de propriedades, na avaliação de 
projetos de investimento sob condições de risco e também na avaliação de instrumentos alternativos no campo da comercialização agrícola. No caso da cafeicultura, decisões sobre sistemas de produção e alternativas de comercialização são de grande importância para o bom manejo da lavoura e consequentemente, do retorno da empresa rural. No entanto, pouco tem sido feito na avaliação econômica de sistemas de produção de café sob condições de risco.

A análise de decisão possibilita ao empresário escolher dentre as alternativas existentes, aquela que apresenta a melhor ação ou decisão ótima. A análise compreende, basicamente, todas as possibilidades de ação e suas respectivas probabilidade de ocorrência.

Azevedo Filho (1988) desenvolveu um "software" (ALEAXPRJ), com objetivo de auxiliar na análise de investimentos sob condição de risco. O programa teve como aplicação inicial a análise de projetos em propriedade citricultora, sendo posteriormente, utilizado também para a cultura de seringueira. Os instrumentais básicos adotados foram técnicas de simulação (Monte Carlo) e critérios de decisões baseados em média e variância.

Peres (1990) utilizou as chamadas árvores de decisão com o objetivo de avaliar a viabilidade da decisão de confinamento de gado de corte. Segundo o autor, as árvores são formadas de nós e ramos, sendo os nós de decisão representados por quadrados e os de chance, ou aleatórios, por círculos. Os ramos que partem dos nós de decisão indicam caminhos (escolhas) que o tomador de decisão segue, mas, os ramos que partem dos nós aleatórios indicam eventos que podem ocorrer com dada probabilidade. Vale lembrar que as alternativas saídas de qualquer nó são exaustivas, ou seja, o somatório das probabilidades dos ramos que partem de um mesmo nó é igual a um. Neste estudo, utilizou-se como critério de decisão a alternativa com maior valor esperado. Em seguida, considerando o grau de aversão ao risco do tomador de decisão, a melhor alternativa seria a que apresentasse maior utilidade esperada. 
Procurando avaliar os méritos dos sistemas de plantio direto e convencional, Salomão (1990) fez uso de critérios de média-variância e dominância de primeira ordem. Segundo os resultados da autora, o plantio direto apresentou-se melhor que o convencional.

Aplicando-se a teoria de decisão na comercialização de café, Peres (1997) procurou avaliar instrumentos alternativos para administrar riscos de preços do produto. Foram consideradas decisões de montar um hedging para assegurar preço, vender uma Cédula do Produto Rural (CPR), vender à vista ou vender à vista em data futura. Utilizou-se árvore de decisão para o processo de modelagem e os critérios de escolha se basearam na maximização do valor esperado e na maximização da utilidade esperada. Seguindo estes mesmos critérios, Matioli (1998) construiu árvores de decisão para auxiliar na escolha sobre irrigação de cana-de-açúcar no estado de São Paulo.

Por fim, cita-se o trabalho realizado por Neves (2000) para o setor citrícola, com objetivo de determinar a economicidade do uso de serviço de fatores de produção em pomares, bem como servir de instrumento para a análise de investimentos em condições de risco de práticas recomendadas para defesa fitossanitária. O autor utilizou técnicas de simulação (Monte Carlo) e avaliou os resultados levando em consideração o critério de média-variância. 


\section{IDENTIFICAÇÃO DE QUESTÕES RELEVANTES EM SISTEMAS DE PRODUÇÃO DE CAFÉ NA REGIÃO SUL DE MINAS GERAIS ATRAVÉS DE GRUPOS FOCAIS ${ }^{4}$}

\section{Resumo}

A produção de café no Brasil vem passando mudanças que têm enfatizado o aprimoramento dos sistemas de produção e o uso de processos que possam incrementar a qualidade. As alternativas existentes para os produtores são numerosas e freqüentemente sugere-se a existência de dúvidas quanto à que seria a mais adequada, dadas as condições existentes em cada região. O trabalho é uma análise exploratória que tem como objetivo caracterizar alternativas relevantes para sistemas de produção de café na região sul de Minas Gerais. Essa análise é desenvolvida, inicialmente, com uma revisão de literatura e consultas a especialistas, visando identificação de questões relevantes para os produtores, sob o ponto de vista dos autores e técnicos consultados. Num segundo momento, visando aprimorar a análise exploratória, utilizou-se o método de "grupos focais", aplicado a grupos de produtores e agrônomos da região de interesse. O objetivo foi o de caracterizar qualitativamente a percepção dos indivíduos quanto as dúvidas mais relevantes com respeito às alternativas de produção existentes. $\mathrm{O}$ trabalho descreve os procedimentos e resultados obtidos, mostrando que as dúvidas mais relevantes percebidas pelos produtores na região estudada diferiram, em alguma medida, daquelas derivadas das análises preliminares, sugerindo questões não consideradas inicialmente como sendo muito relevantes. Os resultados apresentados podem ser úteis para

\footnotetext{
${ }^{4}$ A versão preliminar desse artigo foi publicada em resumo nos anais e na íntegra em CD, no XXXIX Congresso Brasileiro de Economia e Sociologia Rural, realizado em Recife, no mês de agosto de 2001.
} 
orientação de estudos direcionados ao desenvolvimento de novos sistemas de produção de café e ao esclarecimento das questões identificadas.

\section{Summary}

The production of the coffee in Brazil has been going through changes that has emphasizing the improvement of the production systems and the use of the processes that can build up the quality. There are many alternatives for the producers and frequently there are doubts as for what it would be more appropriated, due to the conditions of each region. The study is an exploratory analysis for checking relevant alternatives for coffee production systems in south of Minas Gerais. At first, this analysis was developed with a review of the literature and getting in touch with specialists, searching for identification with relevant questions for the producers, according to the authors and specialists consulted. On a second time, aiming for improving the exploratory analysis, it used the method of "focal groups", applied to groups of producers and agronomists of the interest region. The purpose was describing the qualities of the perception of the people concerning to the doubts more relevant on the alternatives of the production that there are at present. The study describes the actions and the results got, showing that the more relevant doubts realized by the producers in the region studied were different from those that comes from preliminaries analyses, suggesting questions that were not considered as being very relevant, at the beginning of the study. The results presented can be useful for guidance on studies with relation to the development of new systems of coffee production and to clarify the identified questions.

\subsection{Introdução}

O café é uma importante commodity no mercado mundial de produtos agrícolas. Para o Brasil, durante anos, foi o mais tradicional produto da pauta do comércio exterior. Contudo, vem perdendo importância relativa com o aumento das exportações do país. Em 1962, o café respondia por 50\% das receitas de exportação, 
caindo para 35\% em 1970, $14 \%$ em 1980, 4\% em 1990, até atingir 2,8\% em 2000, quando o país exportou US\$1,8 bilhão (Carvalho, 2001). Além da importância financeira com geração de divisas, a cafeicultura se constitui em uma atividade geradora de muitos empregos diretos e indiretos.

No mercado internacional, o café brasileiro também apresentou uma trajetória de queda de participação. Como principais motivos, podem-se citar a falta de qualidade do produto brasileiro, altos custos de produção, endividamento da cafeicultura, problemas climáticos e grandes variações no preço do produto (Farina et al., 1999).

Esses aspectos motivam, em larga medida, um significativo processo de reestruturação do setor cafeeiro no Brasil, caracterizado por uma realocação geográfica das regiões produtoras e mudanças nos conceitos utilizados na produção e beneficiamento, visando melhor eficiência e qualidade final do produto. São numerosas as propostas de sistemas de produção inovadores, que buscam aumento da competitividade por meio de: diferenciação de produto pela qualidade, redução de custos via elevação de produtividade e adoção de novas tecnologias de produção (Martin et al., 1995; Grossi, 1998).

Como essas propostas envolvem investimentos e alterações nas práticas utilizadas tradicionalmente, é natural que existam dúvidas quanto ao seu mérito técnico e econômico, quando consideradas as características peculiares de uma dada região produtora.

O estudo realiza uma análise exploratória que visa caracterizar qualitativamente alternativas de decisão relevantes dentro de sistemas de produção de café na região produtora do sul de Minas Gerais. Segundo Ruiz (1982), o objetivo de uma pesquisa exploratória é a caracterização inicial do problema e sua apropriada formalização. É, portanto, o primeiro estágio da pesquisa científica, não tendo por objetivo resolver de imediato o problema, mas, tão somente apanhá-lo, caracterizá-lo. 
Essa análise exploratória tem por objetivo final, fundamentar outros estudos a partir de um melhor entendimento do problema existente.

Autores consagrados na área de análise de decisões (Hammond et al., 1998a, 1998b) enfatizam a importância de um entendimento adequado do problema, eventualmente, a partir da utilização de técnicas formais que possam propiciar esse melhor entendimento, de forma a prevenir esforços na busca de "solução ótima para o problema errado".

\subsection{Metodologia}

A análise exploratória foi desenvolvida em duas etapas. Primeiro, a partir da literatura existente e consultas informais a especialistas, para um entendimento preliminar, sobre as questões mais relevantes nos sistemas de produção de café. A revisão de literatura considerou em larga medida, além da literatura mais tradicional, trabalhos recentes apresentados no Congresso Brasileiro de Pesquisas Cafeeiras, um dos principais eventos do setor. Nas consultas aos especialistas, procurou-se levantar questões que poderiam ser exploradas em pesquisas posteriores.

A segunda etapa do trabalho teve por objetivo o aprimoramento do entendimento alcançado na primeira etapa, com foco na região definida para desenvolvimento do trabalho (Sul de Minas), por meio de uma pesquisa junto a produtores e agrônomos diretamente ligados à produção de café nessa região. $\mathrm{Na}$ pesquisa, utilizou-se o método do "grupo focal" para caracterizar qualitativamente a percepção dos indivíduos quanto às dúvidas mais relevantes dentro das alternativas de produção.

Os procedimentos metodológicos utilizados são descritos na próxima seção, onde são encontram-se também algumas aplicações dessa técnica qualitativa de pesquisa. 


\subsubsection{Grupo focal}

O grupo focal é um método de pesquisa de cunho qualitativo para coleta de dados. Ele pode ser considerado como um tipo de entrevista em grupo, porém, de forma diferente da entrevista padrão, onde se alternam as perguntas do entrevistador e as respostas do entrevistado. Esse método utiliza sessões grupais e tem como essência a interação de opiniões entre os participantes, a partir de temas que são fornecidos pelo moderador do grupo. A análise sistemática e cuidadosa das discussões vai fornecer pistas e "insights" sobre o assunto alvo da investigação (Krueger, 1994).

Sua maior utilização vem sendo feita por pesquisadores da área de saúde [Westphal et al. (1996), Carlini-Cotrim (1996)] e de marketing [Sette (1999)], sendo considerado um instrumental valioso no campo das pesquisas nessas áreas. Os defensores da técnica argumentam que sua principal vantagem é a possibilidade de se atingir maior número de pessoas ao mesmo tempo, a um custo relativamente baixo e com grande velocidade no fornecimento de dados qualitativos relevantes.

No setor cafeeiro, Sette (1999), utilizou o grupo focal com o objetivo de levantar a imagem do produto junto aos jovens brasileiros, com vistas ao fornecimento de subsídio para futuras estratégias de marketing a serem adotadas no setor, como tentativa de aquecimento do consumo interno de café.

As sessões grupais como método de pesquisa são recomendadas pela maior possibilidade que oferece para se pensar coletivamente sobre um determinado assunto, de interesse e conhecimento de todos presentes. $O$ entendimento qualitativo de uma questão por meio de grupo focal tem como ponto fundamental o uso da tendência humana de formar opiniões e atitudes pela interação social.

A técnica de grupos focais é sugerida para vários propósitos, a saber (Westphal et al., 1996): (a) como etapa qualitativa precedente a outros estudos de caráter quantitativo; (b) como fonte preliminar de informação para elaboração e teste de questionários; (c) como meio para se obter interpretação de um grupo sobre resultados 
obtidos em estudos prévios; (d) internamente às empresas, para discutir políticas salariais, entre outras aplicações. Como desvantagens da técnica podem-se apontar: a possibilidade de existir problemas de interpretação entre os indivíduos (moderador ou membro do grupo) e a dificuldade para generalização dos resultados obtidos.

A amostra utilizada para a realização do grupo é, em geral, intencional. Recomenda que cada grupo contenha, idealmente, de 5 a 10 indivíduos, nunca superando 15 participantes. A escolha dos membros deve ser feita de tal forma que estes apresentem pelo menos uma característica em comum (idade, sexo, ocupação, escolaridade, classe social, etc.), de acordo com o objetivo do estudo. Apesar dessa homogeneidade em um grupo, os estudos geralmente são feitos com diversos grupos, permitindo a identificação de percepções diferentes. O número de grupos necessários vai depender do estudo em questão, tornando-se razoável a partir do momento em que as respostas começam a se repetir e as questões são respondidas.

Para aplicação do método são necessários três "atores": os membros do grupo, cuja função consiste no fornecimento de dados, o moderador e o assistente (observador). Para o moderador, cabe compor um roteiro de questões e criar um ambiente descontraído na coordenação das reuniões para que os participantes possam expressar livremente suas opiniões e sentimentos. $O$ moderador deve, quando necessário, encorajar os participantes e manter a discussão focalizada, retornando ao assunto quando alguém se desviar dele, ou mesmo intervir no discurso quando perceber a presença de monopólio na sessão. Ao observador, cabe a função de captar as informações não-verbais expressas pelos participantes e anotar para, ao final, incorporálas ao que foi gravado durante a sessão.

\subsubsection{Analise dos dados}

Os dois métodos básicos sugeridos (Carlini-Cotrim, 1996) para a análise dos resultados são: (a) os sumários etnográficos e (b) a codificação dos dados via análise de conteúdo. A diferença principal entre eles é que o primeiro método enfatiza as citações textuais dos participantes dos grupos para ilustrar os achados principais da análise e o 
segundo utiliza a descrição numérica para aferir a ocorrência de categorias explicativas que aparecem ou estão ausentes das discussões, e em quais contextos se verificam.

\subsubsection{Procedimentos metodológicos}

Neste estudo foram realizadas sete reuniões com produtores e agrônomos, totalizando 40 indivíduos, sendo 14 engenheiros agrônomos e 26 produtores de café. No convite para a reunião, procurou-se, sempre que possível, separar grupos de pequenos, médios e grandes produtores, com o propósito de padronizar os grupos e evitar qualquer inibição que eventualmente, pudesse ocorrer. A estratificação se baseou em uma reunião junto a pesquisadores da EPAMIG/Lavras , MG, sendo considerados os limites de área plantada de café: menos de 10 ha, de 10 a 30 ha e acima de 30 ha, para a designação das categorias de pequenos, médios e grandes produtores, respectivamente.

Na formação dos grupos, contou-se com o apoio da EPAMIG (Empresa de Pesquisa Agropecuária de Minas Gerais), EMATER-MG (Empresa de Assistência Técnica e Extensão Rural de Minas Gerais) e alguns produtores da região. O Quadro 1 apresenta os tópicos discutidos nas duas primeiras reuniões. 
1. Visão de um sistema de produção de café

1.1. Densidade de plantio (plantios convencionais x não convencionais)

1.2. Irrigação

1.3. Café convencional x especiais (orgânico, cereja descascado, despolpado)

1.4. Mecanização (manejo e colheita)

1.5. Nutrição (adubação química x orgânica)

1.6. Cultivar. É importante? Qual(is)seriam recomendadas?

1.7. Riscos biológicos e climáticos. Acham importante? Quais?

2. O que pensam a respeito de um sistema de produção de café? O que é importante na decisão de plantio?

Quadro 1 - Roteiro de discussão aplicado aos primeiros grupos focais.

Fonte: Dados da pesquisa

Após avaliação das percepções levantadas nas duas primeiras reuniões, fezse então, algumas alterações no roteiro de discussão (Quadro 2). Essas modificações são necessárias, visto que a opinião dos indivíduos vai conduzindo a pesquisa para a investigação de pontos mais relevantes, sendo o restante descartado. 
1. Visão de um sistema de produção de café

1.1. Densidade de plantio (plantios convencionais x não convencionais)

Quais espaçamentos seriam recomendados?

1.2. Irrigação (Qual tipo?)

1.3. Café convencional x Orgânico

Gargalos do sistema?

Tem mercado? Como é?

1.4. Café de terreiro convencional (natural) $\mathrm{x}$ cafés especiais (descascado, despolpado)

O clima influencia na produção dos especiais? Como?

Esta havendo ágio para este café? De quanto?

Como é definido o ágio?

1.5. Peneiras (separar ou fazer bica corrida). Quais peneiras?

O clima influencia a peneira? De que maneira?

1.6. Preços do café daqui a 5 anos? E 10 anos?

2. O que pensam a respeito de um sistema de produção de café? O que é importante na decisão de plantio? Têm mais alguma variável de dúvida?

Quadro 2 - Roteiro de discussão utilizado após a segunda reunião.

Fonte: Dados da pesquisa

A maior dificuldade na aplicação do método foi encontrada na convocação (ou convite) dos indivíduos para as reuniões. Pela experiência deste estudo, recomendase convidar de 10 a 15 ou mais indivíduos, em horário propício e local de fácil acesso a todos, na tentativa de garantir um número mínimo de presentes (pelo menos 4 pessoas). O convite feito por meio de uma instituição ou pessoa física de influência junto aos participantes pode contribuir para aumentar a presença. Nesta pesquisa, mesmo contando com a valiosa ajuda e disposição da EPAMIG e EMATER, algumas reuniões agendadas não foram realizadas por falta de um número mínimo de participantes. Nessas ocasiões, optou-se por entrevistas individuais - aproveitando a presença do(s) 
indivíduo(s) - e, em alguns casos, pequenos grupos de discussão (2 a 3 indivíduos) com base no roteiro do grupo focal.

O oferecimento de algum atrativo (churrasco, brindes) pode favorecer um maior comparecimento dos participantes nas reuniões. Outra alternativa poderia vir da inclusão de grupos focais em eventos científicos (seminários, congressos, dias de campo, etc.) ou qualquer outro meio que o pesquisador encontre para contornar esta dificuldade.

\subsection{Resultados e Discussão}

Um número expressivo de trabalhos sobre sistemas de produção de café foi encontrado na literatura. A maior parte deles, contudo, apresenta um enfoque puramente técnico, que deixa de lado considerações de natureza econômica. Esse fato acaba dificultando uma avaliação mais abrangente dos méritos relativos das tecnologias consideradas e, consequientemente, levando dúvidas aos produtores na adoção de ações alternativas.

Nacif (1997) enfatiza que há um número expressivo de trabalhos publicados que estudam, basicamente, o efeito do adensamento sobre a produção e produtividade (Pádua, 1998; Bartholo, 1998; Carvalho et al., 1997a; Toledo et al., 1992; Siqueira et al., 1990; Viana et al., 1984; Miguel et al., 1979, entre outros). Por outro lado, há carência de estudos mais amplos, procurando entender os méritos técnicos e econômicos das tecnologias utilizadas. Em passado recente, algumas pesquisas foram desenvolvidas

sobre sistemas de processamento ou preparo do café. Contudo, a preocupação novamente se voltou para a questão técnica [(Bartholo e Guimarães (1989, 1997); Carvalho et al., 1997b; Bartholo et al., 1997; Leite, 1998].

Para facilitar a caracterização dos sistemas existentes, considerou-se a descrição e aspectos dos sistemas de produção realizada por Matiello (1995), apresentada no Quadro 3. Essa caracterização facilitou a escolha das questões investigadas na etapa preliminar do trabalho e por ocasião da realização dos grupos focais, sendo formalizadas nos roteiros de discussão utilizados (Quadros 1 e 2). 
Nas consultas realizadas junto a especialistas no setor, verificou-se também uma grande preocupação com variáveis técnicas. No que se refere ao espaçamento da lavoura, foram registradas divergências sobre as práticas ideais. Contudo, o que ficou aparente nesses contatos foi a existência de dois grupos principais de opiniões. De um lado, o grupo dos defensores dos sistemas adensado a super adensado; de outro, o grupo dos defensores do sistema que privilegiam espaçamento mais aberto, principalmente entre linhas (nas "ruas").

Os trabalhos desenvolvidos na revisão de literatura e entrevistas iniciais sugeriram que, dentro das questões mais relevantes consideradas dentro dos sistemas de produção de café, estaria a definição do espaçamento mais apropriado, fruto de divergências acirradas entre especialistas no setor . Além dessa questão, estariam as dúvidas com respeito à prática da irrigação, controle fitossanitário, nutrição da planta e outras mais (Quadro 3). 


\begin{tabular}{|c|c|}
\hline Variáveis & Tecnologias \\
\hline Espaçamento & $\begin{array}{l}\text { 1. Super adensado, } \\
\text { 2. Adensado, } \\
\text { 3. Semi-adensado, } \\
\text { 4. Renque-mecanizado, } \\
\text { 5. Tradicional. }\end{array}$ \\
\hline Manejo dos tratos & $\begin{array}{l}\text { 1. Manual, } \\
\text { 2. Tração animal, } \\
\text { 3. Mecanizado. }\end{array}$ \\
\hline Condução das plantas & $\begin{array}{l}\text { 1. Aberto, } \\
\text { 2. Periodicamente aberto ou com podas, } \\
\text { 3. Sempre fechado. }\end{array}$ \\
\hline Condição climática & $\begin{array}{l}\text { 4. A pleno sol, } \\
\text { 5. Arborizado ou sombreado, } \\
\text { 6. Irrigado. }\end{array}$ \\
\hline Trato nutricional & $\begin{array}{l}\text { 1. Rotineiro (sem adubação), } \\
\text { 2. Químico ou combinação com o orgânico, } \\
\text { 3. Só orgânico. }\end{array}$ \\
\hline Sistema de controle fitossanitário & $\begin{array}{l}\text { 1. Rotineiro (sem controle), } \\
\text { 2. Controle natural (genético ou inimigos naturais), } \\
\text { 3. Via pulverização, } \\
\text { 4. Via solo. }\end{array}$ \\
\hline
\end{tabular}

Quadro 3 - Caracterização dos sistemas de produção de café.

Fonte: Matiello (1995)

Os resultados obtidos no grupo focal, por se tratar de pesquisa qualitativa, foram analisados e interpretados na forma descritiva, por meio de sumários etnográficos. Esses sumários estão resumidos no Quadro 4, onde se encontram também, ordenados, os níveis de dúvida das variáveis abordadas entre os agentes, como sendo: alto, moderado e 
baixo. Na elaboração desse ranking, o nível alto relata questões consideradas duvidosas e que se repetiram em, praticamente, todas as reuniões. O moderado se refere a questões que repetiram com menor intensidade inter e/ou intragrupos e o nível baixo, quando, relativamente, não havia repetição como sendo uma questão duvidosa.

Um resultado interessante, obtido após realização dos grupos focais, foi a observação de poucas dúvidas sobre o espaçamento ideal na cultura do café e outros aspectos técnicos enfatizados na literatura ou pelos técnicos consultados. $O$ que se verificou, de modo geral, foram poucas variáveis polêmicas.

Aspectos como os espaçamentos não foram caracterizados como problema significativo na região sul mineira, mas sim uma questão de preferência dos agentes em face da situação existente. A questão do adensamento estaria, no fundo, muita associada à possibilidade ou não de mecanização, que dependeria fortemente da topografia do terreno, tamanho da propriedade, disponibilidade de mão-de-obra, etc. $O$ grau de adensamento seria uma conseqüência desses aspectos, não havendo dúvidas significativas quando essas características são especificadas. O interesse pela questão do espaçamento por produtores foi aquém da preocupação manifestada na literatura e discussões com especialistas, sendo classificada como uma questão relativamente trivial em função dos aspectos discutidos.

No caso da separação dos grãos por peneira, não se verificou uma preocupação direta dos produtores. No entanto, com a promoção dos cafés especiais por meio de concursos de qualidade e ágios na venda do produto, algumas questões sobre a viabilidade econômica de um aprimoramento da qualidade pela adoção de tecnologias alternativas para processamento e beneficiamento do café (despolpa, separação de bicas, etc.) foram enfatizadas.

Nesse caso particular, ocorreram fatos interessantes. Alguns produtores se reportaram, eventualmente, ao período de gestão de política cafeeira feita pelo IBC, argumentando a falta de reconhecimento pela qualidade. Em ocasiões em que isso ocorreu, as discussões foram fortalecidas e as dúvidas afloraram quanto aos benefícios 
econômicos do investimento em tecnologia que visa ao aumento de qualidade e à diferenciação de produto.

Com respeito à irrigação, em função de percepções diferentes com respeito aos índices pluviométricos da região pesquisada, expressada pelos participantes da pesquisa, foram registradas também algumas dúvidas quanto ao mérito econômico da irrigação da lavoura, nos casos em que essa prática poderia ser adotada. 


\begin{tabular}{|c|c|c|}
\hline Variáveis de estudo & Descrição tecnológica & Nível de dúvida \\
\hline Espaçamento & $\begin{array}{l}\text { 1. Mecanizado, } \\
\text { 2. Não mecanizado, } \\
\text { População de } 4.000 \text { a } 6.000 \text { plantas/ha }\end{array}$ & Moderado \\
\hline Manejo dos tratos & $\begin{array}{ll}\text { 1. } & \text { Manual, } \\
\text { 2. } & \text { Mecanizado. }\end{array}$ & Baixo \\
\hline Condução das plantas & $\begin{array}{ll}\text { 1. } & \text { Aberto, } \\
\text { 2. } & \text { Periodicamente aberto. }\end{array}$ & Moderado \\
\hline Manejo da lavoura & $\begin{array}{ll}\text { 1. A pleno sol, } \\
\text { 2. } \\
\text { Irrigado. }\end{array}$ & Alto \\
\hline Nutrição & $\begin{array}{l}\text { 1. Só químico, } \\
\text { 2. Químico e orgânico, } \\
\text { 3. Só orgânico. }\end{array}$ & Baixo \\
\hline $\begin{array}{l}\text { Sistema de controle } \\
\text { fitossanitário }\end{array}$ & $\begin{array}{l}\text { 1. } \text { Via pulverização, } \\
\text { 2. } \text { Via solo (preventivo), } \\
\text { 3. } \text { Sem controle. }\end{array}$ & Baixo \\
\hline $\begin{array}{l}\text { Café orgânico x } \\
\text { convencional (especial, } \\
\text { natural) }\end{array}$ & $\begin{array}{l}\text { 1. } \text { Orgânico, } \\
\text { 2. Natural, } \\
\text { 3. } \text { Cereja descascado, } \\
\text { 4. } \text { Despolpado. }\end{array}$ & Alto \\
\hline Cultivar & 1. Diversas & Baixo \\
\hline Peneira & $\begin{array}{l}\text { 1. } \text { Bica corrida, } \\
\text { 2. Faz separação por peneira. }\end{array}$ & Moderado \\
\hline
\end{tabular}

Quadro 4 - Sistemas de produção de café no sul de Minas Gerais.

Fonte: Dados da pesquisa

Os resultados obtidos alteraram as próprias perspectivas dos pesquisadores envolvidos com respeito às questões mais relevantes e natureza dos problemas existentes 
dentro de sistemas de produção de café. Dessa forma, mostraram a importância de técnicas exploratórias para melhor direcionamento das pesquisas sobre temas que possam esclarecer, mais satisfatoriamente, as demandas privadas existentes.

Além disso, a pesquisa exploratória junto aos agentes do setor possibilita uma melhor iteração do pesquisador com o objeto de pesquisa, uma aproximação dos valores e cultura dos produtores, uma vivência de campo essencial para a dinâmica do estudo e para o conhecimento da realidade em análise. Enfim, essa aproximação proporcionou uma experiência extremamente relevante, conforme já mencionado, para o direcionamento da pesquisa e para a avaliação relativa de sua importância e aplicação prática no setor estudado.

\subsection{Conclusões}

A pesquisa mostrou que, dentro da região investigada (sul de Minas Gerais), há poucas dúvidas com respeito aos sistemas de produção mais apropriados, especialmente quanto a aspectos associados às técnicas de produção. Pontos mais polêmicos foram encontrados quanto ao uso ou não de irrigação, produção de café orgânico e cafés especiais, assim como a definição dos processamentos (cereja descascado e despolpado).

São escassos, todavia, os estudos econômicos visando à avaliação dessas tecnologias de produção e preparo do produto. A literatura existente tem dado muita atenção para estudos técnicos que acabam enfatizando emas voltados para a forma de produção, deixando de lado não só questões relevantes do ponto de vista do produtor, mas também, a avaliação dos méritos econômicos das tecnologias existentes.

A utilização do grupo focal como técnica de pesquisa exploratória mostrouse útil ao possibilitar uma melhor caracterização das questões prioritárias para futuras pesquisas, do ponto de vista dos agentes envolvidos com a produção de café. 
Algumas limitações sobre a aplicação do grupo focal, em particular relativas ao monopólio da palavra por alguns dos participantes, inibição de outros e desvio de foco, foram verificadas, haja vista o menor grau de controle desse tipo de método em relação à condução de uma entrevista individual. Essas dificuldades, no entanto, foram facilmente controladas com pequenas intervenções do moderador. Um aspecto que contribuiu sobremaneira para o desenvolvimento satisfatório das discussões foi, sem dúvida, o tema proposto, assunto de interesse e conhecimento dos participantes.

A análise dos dados, sob risco de viés na interpretação, foi facilitada pela ocorrência de poucas dúvidas sobre as tecnologias de produção, pelo conhecimento dos participantes a respeito do conteúdo proposto e pelo caráter qualitativo da pesquisa, objetivando caracterizar e identificar demanda dos produtores sobre os sistemas de produção de café.

Dando continuidade à pesquisa, os autores optaram pela elaboração de um modelo de decisão, atendendo à demanda do setor no que se refere a produção de cafés especiais, pelos sistemas de processamento cereja descascado, despolpado (ou desmucilado) e natural. A análise quantitativa e o modelo proposto são apresentados em um outro artigo, que se encontra no próximo capítulo. 


\section{SISTEMAS DE PROCESSAMENTO DE CAFÉ NO SUL DE MINAS GERAIS: UM MODELO DE ANÁLISE DE DECISÃO}

\section{Resumo}

Considerando-se as diversas mudanças que influenciaram o rumo da cafeicultura brasileira nas últimas décadas, é razoável encontrar numerosas alternativas de produção, que podem também ser motivo de dúvida entre os produtores. Baseado em um estudo exploratório, no qual foram levantadas questões de dúvidas entre os produtores de café, o presente trabalho objetiva construir um modelo de análise de decisão frente às alternativas de processamento de café nas formas natural, cereja descascado e despolpado. Foram utilizadas como referencial teórico, teoria e técnicas de análise de decisão, sendo a especificação e formalização do modelo apoiadas por um diagrama de decisão. O trabalho descreve os procedimentos e resultados obtidos, mostrando que a alternativa de produzir cafés de alta qualidade é uma boa opção para os cafeicultores. Esses resultados podem ser úteis para orientação dos produtores e pesquisadores no esclarecimento dos méritos técnicos e econômicos dessa tecnologia de produção.

\section{Summary}

Taking into consideration the several changes that influenced the course of the brazilian coffee growing in the last decades, is reasonable to find numerous alternatives of production that can be a doubt between the producers. Based on a exploratory study, at which were checked questions of doubt between the coffee producers, the present study intends to build up a model of analysis for decision face to the alternatives of processing of coffee on natural way, pulped (coffee) and washed (coffee). It was used as 
reference theoretical, theory and techniques of analysis for decision, and the specification and the form of the model were based on a decision diagram. The study describes the actions and the results obtained, showing that he alternative for producing coffee of high quality is a good option for the coffee producers. These results can be useful for guidance the producers and researchers on explanation of the technical and economical benefits of this technology of production.

\subsection{Introdução}

O parque cafeeiro está implantado no Brasil há quase 200 anos. Nesse período, sofreu mudanças significativas de localização, tecnologias de produção (formação e manejo) e métodos diversos de colheita e pós-colheita.

Frente aos sistemas inovadores que vêm sendo adotados, realizou-se uma pesquisa exploratória junto a produtores e agrônomos no sul de Minas Gerais. Utilizouse o método de "grupos focais", com o intuito de verificar a existência de dúvidas nas tecnologias de produção empregadas na região. Entre as questões levantadas na pesquisa, foram identificadas dúvidas quanto aos méritos econômicos de diferentes sistemas de processamento ou preparo do café. Portanto, a questão demanda um modelo de decisão para auxiliar escolhas relativas a investimentos no âmbito privado, esclarecer conseqüências das tecnologias implantadas e comparar os méritos relativos de cada sistema por meio das técnicas de análise de decisão: valor esperado e utilidade esperada.

\subsubsection{O sistema de preparo do café}

Apesar de sua importância para muitos países em desenvolvimento, o café apresenta alguns problemas específicos, principalmente relacionados com as perdas de qualidade durante o período de pós-colheita. O café colhido constitui-se de uma mistura de frutos verdes, maduros (conhecidos por "cereja"), de frutos secos, folhas, ramos, terra, paus e pedras; deve ser devidamente lavado e depois secado, armazenado e beneficiado. No caso de cafés "cereja descascado" e "despolpado", deverão ainda passar pelo separador de cereja, descascador e desmucilador (este último somente o 
despolpado), antes da secagem dos grãos. Ao conjunto dessas operações dá-se o nome de "preparo do café" (Bartholo, 1997).

Algumas técnicas no processamento dessa rubiácea já vêm sendo adotadas em função da crescente valorização do café de alta qualidade. Como essa decisão envolve investimentos e alterações nas práticas utilizadas tradicionalmente, é natural que haja dúvidas quanto aos seus méritos técnicos e econômicos.

Nesse estudo, procurou-se comparar decisões relativas aos sistemas de preparo de café, que indicam a produção de café natural comparativamente aos cafés cereja descascado ou despolpado. Faz-se então a distinção dos três (Brando, 1999; Barholo et al. 1997):

1) Café natural (natural coffees ou naturals) - é aquele processado por via seca e em que o grão é secado com a polpa e a mucilagem, assim permitindo a transferência do sabor adocicado ao grão. Tipicamente, tal café tem corpo e aroma pronunciados, típico, quase que exclusivamente, dos cafés do Brasil.

2) Café despolpado ou lavado (washed coffees) - é aquele em que tanto a polpa quanto a mucilagem são totalmente removidas e o pergaminho seca sem elas. São bastante comuns entre os produtores da América Central, México, Colômbia, Quênia e África. Quando bem preparados, apresentam bebida suave, mole ou estritamente mole, com corpo e aroma menos pronunciados que os cafés natural e cereja descascado.

3) Café cereja descascado (pulped naturals) - é aquele em que a polpa é completamente removida e a mucilagem não é removida ou removida apenas levemente. O pergaminho seca envolvido pela totalidade ou quase totalidade da mucilagem e, assim, em contato com açúcares que conferem sabor doce ao grão, a exemplo do café natural. $O$ mais comum é que ele apresente tendência às características do natural, porém, com uma xícara mais limpa, isenta de verdes, com doçura típica. 
A Figura 1 descreve os sistemas de processamento de café.

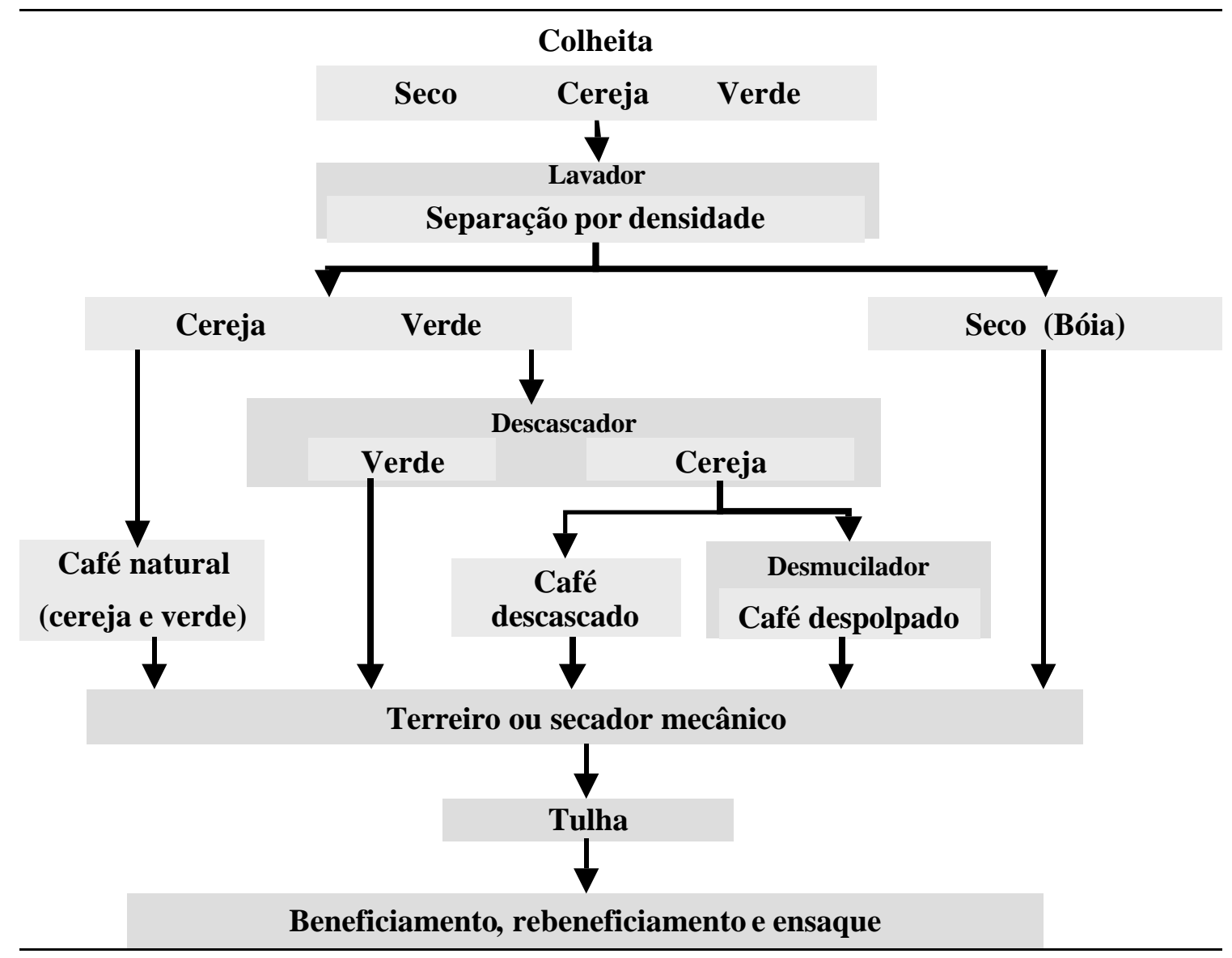

Figura 1 - Esquema de processamento do café.

Fonte: Elaboração do autor

\subsection{Revisão de Literatura}

\subsubsection{O processo de implementação de análise e engenharia de decisão}

Azevedo Filho (op. cit., p.14) apresenta uma metodologia geral para a análise de decisão, ilustrada na Figura 2. As bases para o processo de análise e engenharia de decisões consistem, na teoria de probabilidade, nos axiomas da teoria de decisão e na clareza na representação e comunicação entre os agentes. A primeira é 
utilizada na representação dos eventos aleatórios (incertos) e caracterização dos resultados das possíveis alternativas definidas para o problema.

Os axiomas da teoria de decisão (transitividade, substituição e ordenação) mostram a capacidade do tomador de decisão no ordenamento das alternativas, de acordo com suas preferências, subjetivas, representadas por um mapa de utilidade (Yarri, 1969). Estes axiomas resultam no chamado princípio de Bernoulli, conhecido também como Teorema Fundamental da Teoria da Utilidade de Von Neumann-Morgenstern (Cruz, 1986).

O entendimento adequado do problema constitui o ponto de partida para a análise, sendo fundamental para prevenir esforços na busca de "solução ótima para o problema errado" ou mesmo irrelevante (Hammond et al. 1998a, 1998b).

Definido o problema, a caracterização das alternativas, conseqüências e preferências segue um processo iterativo entre o analista, especialista, tomador de decisão e evidências da literatura, ou seja, na origem do conhecimento. Assim, um modelo de análise de decisão objetiva a ligação entre um estado inicial de dúvidas sobre a ação/decisão apropriada e um estado final de certeza sobre a ação/decisão a ser tomada.

Entre os critérios metodológicos da análise de decisão, podem-se destacar os modelos de maximização do valor esperado e maximização da utilidade esperada. $\mathrm{O}$ primeiro tem um significado particular em economia, pois, um indivíduo que se comportasse como tal, seria classificado como neutro em relação ao risco (Friedman \& Savage, 1948). Este, porém, não é um comportamento esperado para os agricultores, ou para qualquer tipo de empresário. Normalmente, os indivíduos são "avessos" ao risco (Peres, 1990).

Considerando que a decisão do agricultor é estritamente pessoal e tendo em vista os riscos que ele percebe freqüentemente, é natural que ele tenha objetivos bem diversos daquele indivíduo unicamente maximizador da renda e baseia suas decisões em 
critérios de maximização da utilidade esperada (Salomão, 1990; Garcia \& Cruz, 1979; Pacheco, 1985). Essa definição é entendida como sendo "a ênfase que o agricultor dá aos critérios econômicos e psicológicos, que estabelecem suas preferências com respeito à renda e ao risco" (Garcia \& Cruz, 1979).

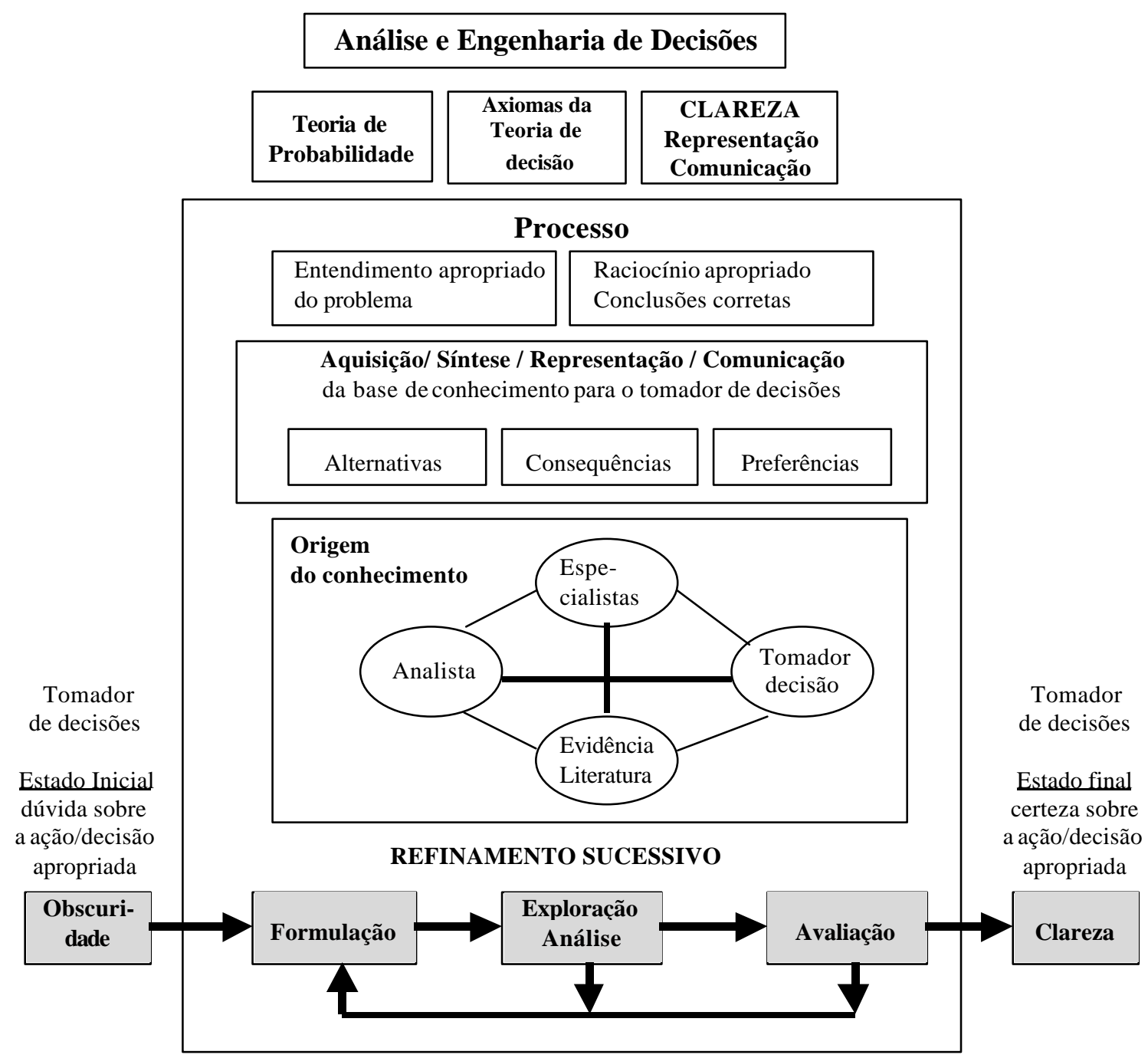

Figura 2 - Esquema de orientação no processo de análise e engenharia de decisões.

Fonte: Azevedo Filho (op. cit., p.14) 
O modelo utilizado é fundamentado no pressuposto de que o agente econômico deseja definir suas ações de forma a maximizar a esperança matemática da função utilidade. A função de utilidade representada pela exponencial negativa é uma função que se aproxima bastante das análises de utilidade aplicada à agricultura (Anderson et al., 1977), além da vantagem de evidenciar de forma clara o coeficiente de aversão ao risco relativo (Azevedo Filho, 2001).

Kallberg \& Ziemba (1979) mostram a similaridade da solução ótima de problemas envolvendo diferentes funções de utilidade sob idêntico coeficiente de aversão ao risco relativo. Ou seja, a solução ótima resultante da maximização da esperança da utilidade pode estar muito mais dependente da magnitude do coeficiente de aversão relativo ao risco que propriamente da especificação da função utilidade.

A função exponencial é descrita conforme a equação (3.1), em que $W$ representa a riqueza do agente, wo é uma proxy para essa riqueza e $R$ o coeficiente de aversão ao risco relativo.

$$
u(W)=-e^{-R \frac{w}{w_{0}}}
$$

O uso do coeficiente de aversão ao risco relativo é conveniente pelo fato de existir alguma evidência empírica sobre a magnitude do valor de $\mathrm{R}$ no mundo real. Alguns autores argumentam que valores realistas para $R$ estão entre 0 e 10 , mais comumente no intervalo entre 0,5 e 6 , em que 0 representa a situação na qual não há aversão ao risco e 10 , uma aversão ao risco extrema ${ }^{5}$.

\subsubsection{Diagramas de decisão}

O diagrama de decisão (ou diagrama de influência) foi desenvolvido originalmente por R. Howard (Howard \& Matheson (1984), Howard (1990)) e

\footnotetext{
5 Para mais detalhes sobre caracterização dessa função, veja Azevedo Filho (2001). Para argumentos suportando a colocação sobre os valores razoáveis para R, veja Markovitz, Reid e Tew (1994) e Lence (1995).
} 
formalizado por R. Shachter (1986, 1987). Trata-se de um instrumento complementar ao uso de árvores de decisão.

Essa representação é totalmente fundamentada nas teorias de decisão e de probabilidades, e conveniente para implementação em software. Aplica-se também a problemas complexos de decisão, por meio de uma linguagem gráfica relativamente inteligível por pessoas envolvidas com o problema sem grande treinamento em métodos quantitativos.

O diagrama pode ser utilizado em diferentes etapas no processo de análise da decisão. Nas fases iniciais, é utilizado como uma ferramenta para análise qualitativa, visando facilitar o entendimento do problema pelos agentes envolvidos e, nas fases finais, para análise quantitativa, a partir da especificação das variáveis em termos de valores, probabilidades e relações funcionais. Essa fase usualmente envolve a especificação das preferências e indicadores utilizados para avaliação dos méritos das alternativas.

Todo diagrama de decisão, totalmente especificado, espelha uma distribuição conjunta de probabilidade. Em problemas que utilizam variáveis discretas, é possível converter um diagrama de decisão em uma árvore de probabilidades (ou árvore de decisão) e vice-versa. Na árvore de probabilidades/decisão, a estrutura do problema fica escondida dentro da árvore, podendo dificultar a modelagem em problemas com muitas variáveis.

No diagrama de decisão, a estrutura do problema fica facilmente disponível para observação e manipulação, o que acaba tornando esse instrumento conveniente para a representação em interfaces gráficas de programas desenvolvidos para apoio à análise de decisão.

Os diagramas de decisão utilizam elementos, conforme os ilustrados na Figura 3, em que o círculo significa incerteza, o quadrado decisão, o círculo com dupla 
borda é um valor determinístico e o hexágono, a função objetivo. A seta contínua indica condicionamento e a pontilhada, informação.

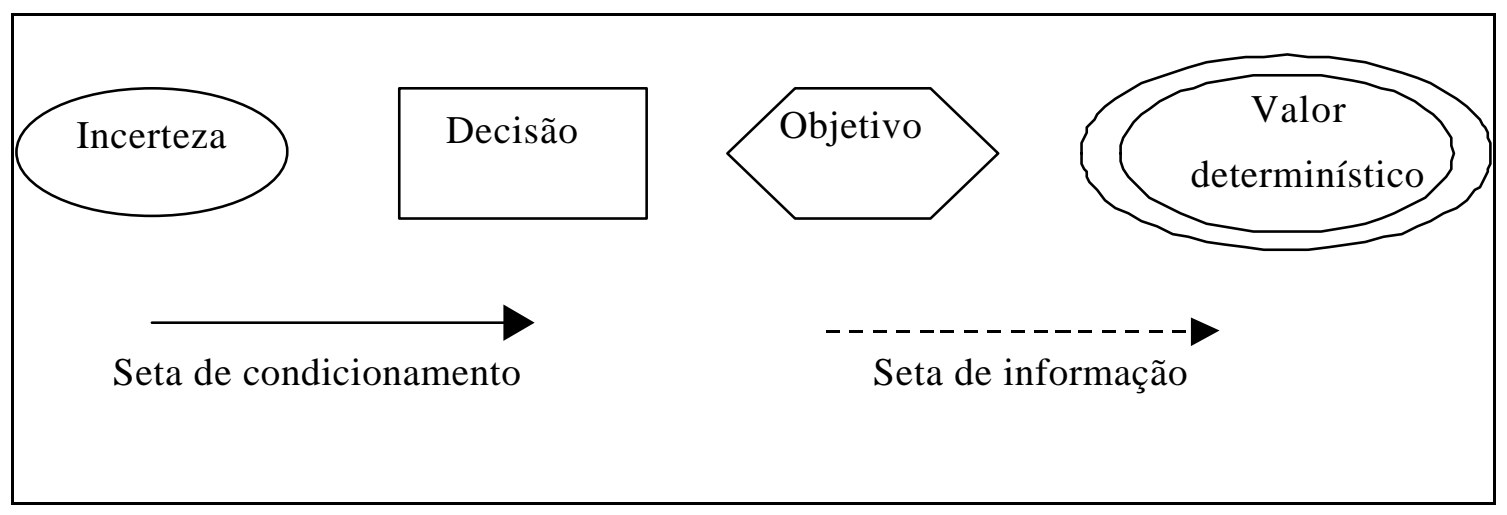

Figura 3 - Elementos gráficos dos diagramas de decisão.

Fonte: Elaboração do autor

\subsection{Metodologia}

\subsubsection{Modelo analítico}

O levantamento e caracterização do problema abordado foi resultado de uma pesquisa exploratória, dividida em duas etapas. Primeiro, a partir da revisão da literatura sobre sistemas de produção de café e, posteriormente, complementada por meio de uma pesquisa qualitativa, realizada junto a produtores de café e engenheiros agrônomos, por meio da técnica de "grupos focais".

O modelo proposto, original, é composto de uma série de variáveis interrelacionadas, de decisão ou incerteza, causadoras de influência ou não, baseando-se em uma função objetivo de maximização da receita líquida (ausência de risco) e maximização da utilidade esperada (presença de risco). O modelo procurou espelhar uma decisão para um período de dez anos, buscando caracterizar todas as variáveis com base nessa perspectiva temporal. 
A variável de decisão (representada pelo retângulo na Figura 4) sobre sistema de processamento do café foi caracterizada em quatro sistemas: natural tradicional, natural especial, cereja descascado e despolpado ${ }^{6}$.

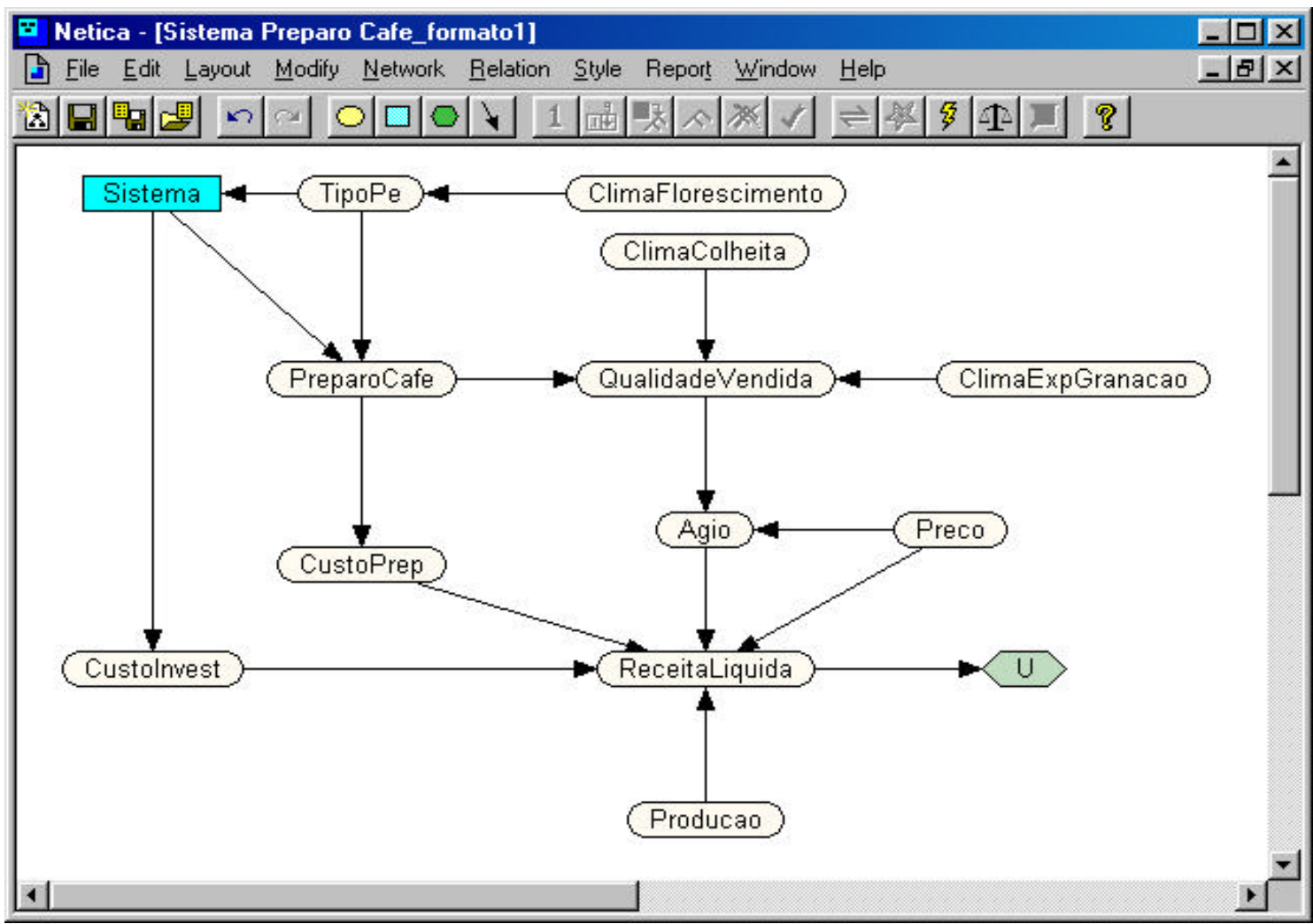

Figura 4 - Apresentação do modelo de decisão para sistemas de preparo do café.

Fonte: Elaboração do autor

Partindo da variável de decisão, procurou-se formalizar o modelo considerando-se as variáveis mais importantes envolvidas nos sistemas ou que os influenciam. Essas variáveis foram identificadas por meio da pesquisa exploratória e

\footnotetext{
${ }^{6}$ A diferença básica entre os sistemas naturais é que, no segundo (natural especial), há um maior cuidado pós-colheita e uma preparação maior do café, passando pelo rebenefício, separação de peneiras e retirada dos grãos verdes e defeituosos, diferente do que é feito no sistema tradicional, quando o produto é vendido bica corrida. Para os outros sistemas, além dessa preparação antes da venda (que envolve custo), demandam-se investimentos em descascador de cereja e desmucilador, este último apenas para o café despolpado.
} 
consultas posteriores (e freqüentes) junto a produtores e engenheiros agrônomos. A vivência de campo e a facilidade de representação por meio de diagramas (facilitando a comunicação entre os agentes) foram de suma importância na elaboração do modelo.

O modelo proposto é apresentado na Figura 4, onde cada variável de incerteza pode assumir diferentes "estados da natureza" como resultados de um evento aleatório. Para as variáveis de decisão são definidas as possíveis alternativas do agente.

No Quadro 5, são descritas as variáveis relacionadas ao processo de produção e tecnologias nele empregado e as variáveis climáticas, que irão afetar direta e indiretamente a tecnologia de produção, a qualidade do café e, conseqüentemente, a definição de seu preço final (incluindo ágio/deságio). No Quadro 6 estão as variáveis relacionadas diretamente com o retorno financeiro. 


\begin{tabular}{|c|c|c|}
\hline Variável & Descrição & Estado da natureza \\
\hline Sistema & $\begin{array}{l}\text { Variável de decisão } \text { sobre } \\
\text { processamento do café }\end{array}$ & $\begin{array}{l}\text { 1. Natural } \\
\text { (tradicional ou } \\
\text { especial), } \\
\text { 2. CerejaD, } \\
\text { 3. Despolpado, }\end{array}$ \\
\hline Tipo Pe & $\begin{array}{l}\text { Refere-se ao estágio de maturação do café } \\
\text { que será colhido }\end{array}$ & $\begin{array}{l}\text { 1. Bóia, } \\
\text { 2. Cereja, } \\
\text { 3. Verde, }\end{array}$ \\
\hline Preparo Cafe & $\begin{array}{l}\text { É o processamento feito no café após a } \\
\text { colheita. De acordo com o método, ocorre } \\
\text { a separação ou não dos cafés verde, cereja } \\
\text { e seco e serve de parâmetro para a } \\
\text { quantidade de cada tipo. }\end{array}$ & $\begin{array}{l}\text { 1. Cereja verde, } \\
\text { 2. Bóia, } \\
\text { 3. Cerejadesc, } \\
\text { 4. Despolpado, } \\
\text { 5. Verde, }\end{array}$ \\
\hline Qualidade Vendida & $\begin{array}{l}\text { Refere-se à qualidade do café que será } \\
\text { vendido, após todo o processamento. } \\
\text { 1. Tipo } 2 \text { a } 3 \text {, bebida mole acima, peneira } \\
16 \text { acima; } \\
\text { 2. Tipo 6, bebida dura, bica corrida. } \\
\text { 3. Tipo inferior ao } 6 \text {, bebida riado pra } \\
\text { pior, peneira } 13 \text { com respectivos defeitos. }\end{array}$ & $\begin{array}{l}\text { 1. Alta, } \\
\text { 2. Média, } \\
\text { 3. Baixa, }\end{array}$ \\
\hline Clima Florescimento & $\begin{array}{l}\text { Refere-se ao clima que irá influenciar no } \\
\text { florescimento do cafeeiro (set./out.) }\end{array}$ & $\begin{array}{l}\text { 1. Bom, } \\
\text { 2. Ruim, }\end{array}$ \\
\hline Clima Colheita & $\begin{array}{l}\text { Refere-se ao clima durante o período da } \\
\text { colheita (mai./ago.). }\end{array}$ & $\begin{array}{l}\text { 1. Bom, } \\
\text { 2. Ruim, }\end{array}$ \\
\hline Clima Exp Granação & $\begin{array}{l}\text { Refere-se ao clima no período de } \\
\text { expansão e granação dos frutos (nov./fev.) }\end{array}$ & $\begin{array}{l}\text { 3. Bom, } \\
\text { 4. Ruim, }\end{array}$ \\
\hline
\end{tabular}

Quadro 5 - Variáveis relacionadas à tecnologia de produção e clima.

Fonte: Elaboração do autor 


\begin{tabular}{|c|c|c|}
\hline Variável & Descrição & Estado da natureza \\
\hline Custo Prep & $\begin{array}{l}\text { Refere-se ao custo para preparar um café } \\
\text { de alta qualidade. É aplicado apenas nos } \\
\text { cafés superiores } \quad \text { (cereja descascado, } \\
\text { despolpado e o cereja com verde do } \\
\text { processamento } \quad \text { natural) e inclui } \\
\text { rebenefício e eliminação de defeitos. }\end{array}$ & $\begin{array}{l}\text { 1. } \text { Bóia, } \\
\text { 2. Verde, } \\
\text { 3. Cerejaverde, } \\
\text { 4. CerDesc, } \\
\text { 5. CerDesp, }\end{array}$ \\
\hline Custo Invest. & $\begin{array}{l}\text { Refere-se ao custo de investimento em } \\
\text { máquinas: descascador e/ou desmucilador } \\
\text { (degomador). }\end{array}$ & $\begin{array}{l}\text { 1. Desp, } \\
\text { 2. CerejaDesc, } \\
\text { 3. Natural. }\end{array}$ \\
\hline Preço & $\begin{array}{l}\text { Preço do café padrão de negócio na região } \\
\text { (tipo 6, bebida dura). }\end{array}$ & 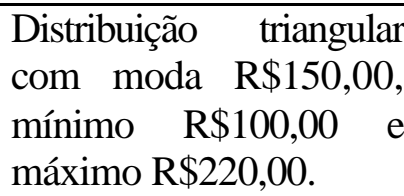 \\
\hline Ágio & $\begin{array}{l}\text { Refere-se ao ágio e deságio na venda do } \\
\text { café sobre o preço padrão. Varia de }-40 \% \\
\text { (deságio) até }+40 \% \text {. }\end{array}$ & $\begin{array}{l}\text { A40; A30; A20; A10; } \\
\text { D10; D20; D30; D40. }\end{array}$ \\
\hline Produção & $\begin{array}{l}\text { Refere-se à produção da propriedade em } \\
\text { questão. }\end{array}$ & $\begin{array}{l}\text { Distribuição triangular, } \\
\text { com moda igual a } \\
5.600 \text { sacas, valor } \\
\text { máximo } 7.200 \text { e } \\
\text { mínimo } 4.000 \text { sacas de } \\
\text { café de } 60 \text { quilos, }\end{array}$ \\
\hline Receita Liquida & $\begin{array}{l}\text { Refere-se à receita obtida com a venda do } \\
\text { café, deduzidos os custos de investimento } \\
\text { e preparação do café. }\end{array}$ & \\
\hline$\overline{\mathrm{U}}$ & $\begin{array}{l}\text { Refere-se à função objetivo do modelo, } \\
\text { que considera a melhor decisão aquela que } \\
\text { maximiza a receita líquida ou a utilidade } \\
\text { esperada. }\end{array}$ & \\
\hline
\end{tabular}

Quadro 6 - Variáveis relacionadas com o retorno financeiro do investimento.

Fonte: Elaboração do autor

\subsubsection{Procedimentos para obtenção dos dados}

O levantamento dos dados foi feito com base em séries históricas e consultas a empresas, produtores e agrônomos. Os dados referentes a custo de investimento foram levantados junto à empresa Pinhalense S.A., em Patrocínio, MG, tendo os valores foram 
distribuídos pelo período de 10 anos, a uma taxa de juros de 11,95 \% a. a. (financiamento de máquinas junto ao Banco Bradesco S/A - modalidade Finame).

O custo de preparação do café (benefício, rebenefício e eliminação de defeito) baseou-se nas informações da empresa Minas Coffee Armazéns Gerais, localizada no município de Santo Antônio do Amparo, MG.

Os dados climáticos foram retirados de uma série histórica, atualizada diariamente, por um agrônomo do extinto Instituto Brasileiro do Café (IBC), no município de Santo Antônio do Amparo, sul de Minas Gerais, onde está sediada a fazenda utilizada para a aplicação do modelo. Com base na série climática, a caracterização dos estados, boa e ruim, foi elaborada com o apoio técnico de pesquisadores da Empresa de Pesquisa Agropecuária de Minas Gerais (EPAMIG).

O restante dos dados foi coletado junto ao proprietário da fazenda "Café Sul de Minas" (nome hipotético), havendo ainda uma iteração direta com agrônomos buscando alcançar maior rigor possível. Ressalta-se que muitos dados se basearam na percepção e experiência dos indivíduos, inclusive no comportamento dessas variáveis para os próximos anos. Para as variáveis preço e produção, assumiu-se uma distribuição triangular em consonância com o esperado pelo tomador de decisão.

Para medir o grau de aversão relativo ao risco, a ser incluído na função utilidade descrita na eq. (3.1), utilizou-se um exemplo relativamente simples, sugerido em Azevedo Filho (2001). Foi perguntado ao agente sobre o valor crítico de probabilidades $p$ que tornariam equivalentes as seguintes alternativas: (a) permanecer com sua receita atual wo e (b) aceitar participar de um jogo, cujo resultado seria definido por um sorteio, onde o agente receberia duas vezes sua receita, ou seja, $2 \mathrm{w}_{0}$, com probabilidade $p$ e metade de sua receita, ou seja, 0,5 $\mathrm{w}_{0}$, com probabilidade (1- $p$ ). A receita informada pelo produtor foi de $\mathrm{R} \$ 700$ mil e o valor de $p$ que o levaria a participar do jogo foi de 0,8. Com esse valor, estimou-se o coeficiente de aversão relativo ao risco, igual a 3 . 


\subsubsection{Fazenda "Café Sul de Minas"}

A fazenda "Café Sul de Minas" possui 1.090 hectares e está localizada no

município de Santo Antônio do Amparo, sul de Minas Gerais. Tem 200 hectares plantados com café e o restante distribuído nas culturas de milho, eucalipto, cana-deaçúcar, pastagens e matas.

\subsection{Resultados e Discussão}

\subsubsection{Modelo de maximização do valor esperado}

Analisando-se os resultados dos sistemas alternativas de processamento do café, verificou-se a superioridade da decisão pela produção de cafés especiais, de acordo com os dados da Tabela 3. Considerando o valor esperado médio de cada decisão, os processamentos, despolpado, cereja descascado e natural especial (bem preparado), foram superiores ao natural tradicional em 11,1\%, 10,5\% e 7,5\%, respectivamente. Esse resultado fez com que a decisão dominada (natural tradicional) fosse abandonada e os esforços centrados nas demais. É importante salientar que as decisões foram robustas ao comportamento do preço e da produção, dentro dos intervalos definidos.

Para os processamentos especiais verifica-se também superioridade do café despolpado e do cereja descascado sobre o natural. O diferencial, contudo, é menor (mas ainda superior) quando se verifica a ocorrência de clima ruim no período de florescimento e/ou expansão e granação dos frutos. Esse comportamento reflete o fato do clima, neste período, influenciar a maturação e dimensão do grão, afetando sua qualidade e, conseqüentemente, o ágio (prêmio) sobre o preço de mercado, tornando menos atrativa a produção dos cafés que demandam maiores investimentos.

Quando comparamos as decisões relativas ao processamento cereja descascado e despolpado, verifica-se uma dominância do último. O maior diferencial entre eles ocorre quando se verifica a informação de clima ruim (ou chuvoso) no período de colheita. Este fator decorre da circunstância de o café despolpado (ou desmucilado) 
responder melhor a situações de clima ruim nesta época, pois, o grão fica menos sujeito a processo de fermentação e consequentemente, à perda de qualidade.

$\mathrm{Na}$ Tabela 3, apresentam-se os principais resultados, com base em uma análise de sensibilidade considerando alguns cenários que, eventualmente, podem ocorrer.

Tabela 3. Modelo de maximização do valor esperado: principais resultados (Em R $\$$ mil).

\begin{tabular}{lrrrr}
\hline Estado da naturezaldecisão & NT* & NE & CD & D \\
\hline Receita média & 809,8 & 870,6 & 894,7 & 899,7 \\
Clima florescimento ruim & 805,3 & 859,3 & 862,7 & 866,4 \\
Clima florescimento bom & 811,6 & 875,2 & 907,4 & 913,0 \\
Clima exp/granação ruim & 787,4 & 854,5 & 875,1 & 877,9 \\
Clima exp/granação bom & 811,7 & 872,0 & 896,3 & 901,5 \\
Clima colheita ruim & 782,5 & 829,1 & 865,5 & 875,6 \\
Clima colheita bom & 811,4 & 873,0 & 896,3 & 901,1 \\
Preço 100/120 & 576,1 & 639,3 & 663,9 & 669,2 \\
Preço 180/200 & $1.015,0$ & $1.066,0$ & $1.086,0$ & $1.091,0$ \\
Produção 4200 & 614,6 & 662,9 & 680,8 & 684,7 \\
Produção 7000 & $1.014,0$ & $1.071,0$ & $1.094,0$ & $1.099,0$ \\
\hline
\end{tabular}

*NT=Natural tradicional; NE=Natural especial; $\mathrm{CD}=$ Cereja descascado; $\mathrm{D}=$ despolpado.

Fonte: Elaboração do autor

A escolha pela produção de café despolpado, embora se apresente como a alternativa dominante, se depara com uma dificuldade na comercialização do grão. É indicado disponibilizar este café no mercado mais cedo, período de junho a agosto, com o objetivo de encontrar melhores cotações. Isso porque, nessa época, ainda não estão 
sendo comercializados os lavados colombianos nem os cafés da América Central, tradicionais produtores de café despolpado.

Sabendo que o investimento em equipamentos para produzir café despolpado possibilita também a produção de cereja descascado e considerando que o resultado obtido nos dois sistemas não apresentou diferença muito elevada, pode-se, eventualmente, adotar a estratégia de preparar os primeiros cafés da colheita pelo sistema despolpado. Aproveita-se, assim, a época em que o Brasil está "sozinho" no mercado. O restante será preparado pelo sistema cereja descascado. O produtor pode, ainda, de acordo com sua preferência, optar pela produção e comercialização do café cereja descascado, já que a diferença entre os dois foi pequena. Isso será muito influenciado pelo momento das negociações, optando pela produção daquele que apresente maior viabilidade comercial e que atenda melhor a seus compradores.

Uma boa alternativa de venda de parte da produção está nos concursos de qualidade, realizados anualmente no Brasil. Os dois principais são o promovido pela torrefadora italiana Illycafê e o da Associação Brasileira de Cafés Especiais (ABCE ou, em inglês, BSCA). Os cafés processados pelo método cereja descascado têm tido boa performance e o ágio sobre o preço dos lotes classificados tem sido excepcional, chegando a 400\%, em alguns casos. No primeiro concurso citado, a própria Illycafé compra os lotes classificados (com ágio) e paga um prêmio em dinheiro para os produtores. No segundo, os melhores cafés participam de um leilão virtual onde estão compradores de todo o mundo.

A estratégia de participar desses eventos possibilita, no âmbito micro, a abertura de mercado para o produtor e no macro, uma melhoria da imagem do café brasileiro no mercado internacional.

\subsubsection{Modelo de maximização da utilidade esperada}

Considerando que os indivíduos são normalmente avessos ao risco e suas decisões são estritamente pessoais, parte-se do pressuposto de que o agente econômico 
deseja definir suas ações, de forma a maximizar a esperança matemática da função utilidade, aqui representada pela exponencial negativa.

A partir desse critério, não foi verificada mudança no resultado do modelo, que também refletiu a dominância da decisão de produzir um café especial, seja processado por via natural, despolpado ou cereja descascado. Entre eles, a opção dominante, e que também se apresentou robusta a variações no preço e na produção, foi a produção de café despolpado, seguido pela produção de café cereja descascado e, por último, café natural.

Utilizando-se o diagrama para fazer algumas simulações, foram encontrados os resultados descritos na Tabela 4. A decisão de produzir o café despolpado foi dominante em todos os casos, exceto na ocorrência de clima ruim para o florescimento.

Neste caso, a decisão de produzir o café natural, também de alta qualidade (café natural bem preparado, com cuidados pós colheita, rebenefício e catação de defeitos - ver variável CustoPrep no Quadro 6) foi superior às demais. Essa verificação reflete o efeito climático, neste período, sobre a maturação do grão (quanto pior o florescimento, mais desuniforme fica o café, mais verde e bóia, relativamente ao cereja), afetando negativamente sua qualidade, e conseqüentemente, o ágio (prêmio) sobre o preço de mercado. Essa diferença aumenta à medida que o indivíduo se manifesta mais avessos ao risco, ou seja, quanto maior sua aversão ao risco, menor a disposição em investir e vice-versa. 
Tabela 4. Análise de sensibilidade no modelo de maximização da utilidade esperada.

\begin{tabular}{lcccc}
\hline Estado da naturezaldecisão & NT* & NE & CD & D \\
\hline Utilidade média & $(0,0440)$ & $(0,0385)$ & $(0,0358)$ & $(0,0354)$ \\
Clima florescimento ruim & $(0,0452)$ & $(0,0403)$ & $(0,0408)$ & $(0,0405)$ \\
Clima florescimento bom & $(0,0436)$ & $(0,0378)$ & $(0,0338)$ & $(0,0334)$ \\
Clima exp/granação ruim & $(0,0497)$ & $(0,0419)$ & $(0,0392)$ & $(0,0391)$ \\
Clima exp/granação bom & $(0,0436)$ & $(0,0383)$ & $(0,0355)$ & $(0,0351)$ \\
Clima colheita ruim & $(0,0510)$ & $(0,0466)$ & $(0,0408)$ & $(0,0399)$ \\
Clima colheita bom & $(0,0436)$ & $(0,0381)$ & $(0,0355)$ & $(0,0351)$ \\
Preço 100/120 & $(0,0949)$ & $(0,0827)$ & $(0,0768)$ & $(0,0757)$ \\
Preço 180/200 & $(0,0158)$ & $(0,0141)$ & $(0,0132)$ & $(0,0130)$ \\
Produção 4200 & $(0,0842)$ & $(0,0739)$ & $(0,0695)$ & $(0,0688)$ \\
Produção 7000 & $(0,0203)$ & $(0,0179)$ & $(0,0165)$ & $(0,0163)$ \\
\hline
\end{tabular}

* NT=Natural tradicional; NE=Natural especial; $\mathrm{CD}=$ Cereja descascado; $\mathrm{D}=$ despolpado. Fonte: Elaboração do autor

Considerando diferentes graus de aversão ao risco, verifica-se também uma mudança na utilidade do agente e, conseqüientemente, nas variáveis dominantes. Admitindo o grau de aversão ao risco $(\mathrm{R})$ variando de 0 a 10 , em que 0 representa a situação na qual não há aversão ao risco e 10 um aversão ao risco extrema, encontram-se os resultados apresentados no Gráfico 2. Tais resultados mostram a relação negativa entre aversão ao risco e investimento, ou seja, à medida que a aversão ao risco do agente aumenta, menos atrativa fica sua decisão de investimento. 


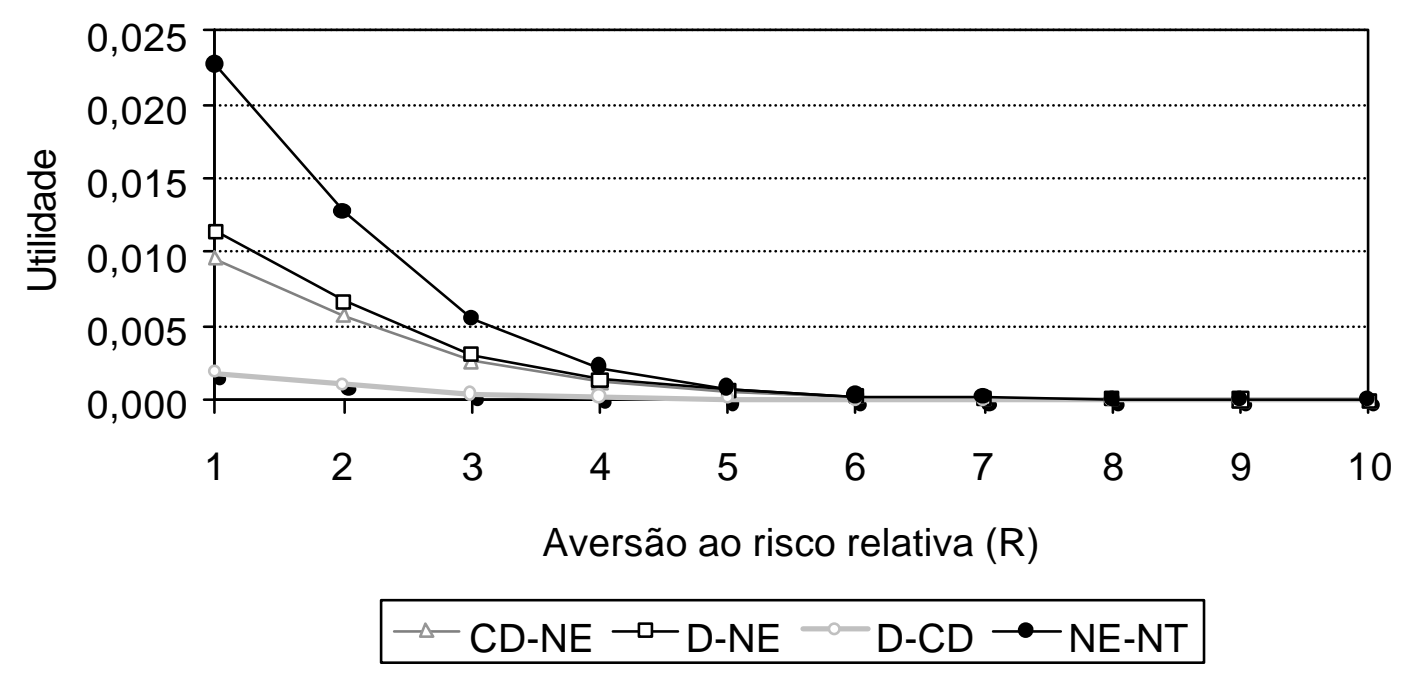

Gráfico 2 - Grau de aversão relativa ao risco e utilidade esperada para os sistemas de processamento do café.

$\mathrm{NT}=$ Natural tradiconal; $\mathrm{NE}=$ Natural especial, $\mathrm{CD}=$ Cereja descascado; $\mathrm{D}=$ despolpado.

Fonte: Elaboração do autor

\subsection{Conclusões}

A produção de café vem passando, nos últimos anos, por um processo de reestruturação, que inclui novas técnicas de produção, procurando garantir maior competitividade ao setor. As alternativas existentes para os produtores são numerosas e, freqüentemente, existe dúvida quanto à que seria mais adequada.

Uma dessas dúvidas se refere à produção de cafés especiais, seja cereja descascado, despolpado ou, mesmo, o café natural bem preparado. Estes sistemas foram caracterizados e avaliados técnica e economicamente no presente estudo.

A decisão de produzir um café especial apresentou-se como boa alternativa para os produtores do sul de Minas Gerais. Entre os alternativos sistemas de processamento, a decisão que indica a produção do café despolpado e/ou a do cereja 
descascado foram superiores à decisão pelo processamento natural. Entre os sistemas despolpado e cereja descascado, a decisão pelo primeiro dominou sobre o segundo, porém, com um diferencial de receita pequeno.

Para todos os cenários desenvolvidos, os cafés especiais apresentam-se superiores. O diferencial de receita é menor quando as condições climáticas são ao florescimento e à expansão/granação dos frutos. O modelo está bastante coerente com a realidade, de acordo com a avaliação de especialistas e tomadores de decisão, podendo ser aplicado, inclusive, em outras regiões, a partir de adaptações necessárias para atender às características regionais ou locais.

A utilização do modelo de maximização de utilidade esperada também foi muito relevante pela caracterização e consideração da aversão ao risco do tomador de decisão. Esse modelo é bastante conveniente pois, de acordo com o comportamento do indivíduo em relação ao risco, diferentes decisões podem ser tomadas. Isso reflete o fato de que a decisão do agricultor é estritamente pessoal e ele pondera critérios subjetivos que traduzem-se em objetivos bem diversos daquele indivíduo unicamente maximizador da renda.

Em atenção ao objetivo geral do trabalho, que foi o de desenvolver um modelo para avaliação de sistemas de preparo de café, útil para análise da viabilidade econômica dos sistemas; para auxiliar decisões relativas a investimentos no âmbito privado; esclarecer conseqüências das tecnologias implantadas, e comparar os méritos relativos de cada sistema por meio das técnicas de análise de decisão (valor esperado, utilidade esperada), pode-se considerar que foram devidamente atendidos. Isso porque foram caracterizados os sistemas e comparados entre si, economicamente, por meio das referidas técnicas de análise de decisão.

Quanto ao objetivo específico de um modelo de decisão, pode-se concluir que também foi atendido, já que foi possível identificar com clareza a melhor ação e/ou decisão a ser tomada, partindo de um estágio inicial de dúvida. 


\section{CONCLUSÕES GERAIS}

A visão global do trabalho apresentou-se muito interessante, a medida que utilizou de instrumentos metodológicos que foram se completando no decorrer da pesquisa. Ela inicioutse com revisão da literatura passando para o levantamento de demanda junto aos produtores de café e a resolução do problema de decisão.

Percebeu-se, no desenrolar da pesquisa, que a literatura existente tem dado muita atenção para estudos técnicos que acabam enfatizando temas voltados para a forma de produção. De outro modo, deixam de lado questões relevantes que são demandadas pelos produtores. Via pesquisa qualitativa foi possível verificar que, na região investigada (Sul de Minas Gerais), existem poucas dúvidas com respeito aos sistemas de produção mais apropriados, especialmente quanto a aspectos associados às técnicas de produção.

Pontos mais polêmicos foram encontrados quanto ao uso ou não de irrigação, produção de café orgânico e cafés especiais, assim como a definição dos processamentos (cereja descascado e despolpado). São escassos, todavia, os estudos econômicos visando a avaliação dessas tecnologias de produção e preparo do produto.

A utilização do grupo focal como técnica de pesquisa exploratória, mostrouse útil e muito conveniente, ao possibilitar uma melhor caracterização das questões mais prioritárias para futuras pesquisas, sob o ponto de vista dos agentes envolvidos com a produção de café.

Quanto aos resultados do modelo de decisão, foi possível identificar que a decisão em produzir um café especial apresentou-se como boa alternativa para os 
produtores do Sul de Minas Gerais. Os sistemas de processamento do café pelos métodos despolpado e/ou cereja descascado foram superiores à decisão pelo processamento natural. Entre os sistemas despolpado e cereja descascado, a decisão pelo primeiro dominou sobre o segundo, porém, com um diferencial de receita pequeno.

Para todos os cenários possíveis, caracterizados no modelo, os cafés especiais foram superiores, com menor diferencial de receita frente à constatação de clima desfavorável ao florescimento e expansão/granação dos frutos. O modelo se mostrou, de acordo com a avaliação de especialistas e tomadores de decisão, bastante coerente com a realidade, podendo ser utilizado, inclusive, em outras regiões, a partir de adaptações necessárias para atender a características específicas do local.

A utilização do modelo de maximização de utilidade esperada foi muito relevante, pela caracterização e consideração da aversão ao risco do tomador de decisão. Esse modelo é bastante conveniente, pois, de acordo com o comportamento do indivíduo em relação ao risco, diferentes decisões podem ser tomadas. A solução encontrada nesse modelo se comportou em linha com a do modelo de maximização do valor esperado.

Em atenção aos objetivos propostos pelo trabalho, os dois primeiros: (i) levantar e caracterizar sistemas alternativos de produção de café na região sul de Minas Gerais, e, (ii) levantar e caracterizar dúvidas, dos produtores, dentro dos sistemas encontrados, que foram atendidos na primeira parte da pesquisa, detalhada no capítulo 3. Quanto aos demais objetivos, (iii) levantar dados técnicos e econômicos dos sistemas selecionados, (iv) modelar as conseqüências econômicas desses sistemas e (v) comparar os méritos relativos de cada um, por meio das técnicas associadas à análise de decisão (valor esperado e utilidade esperada), verificou-se também que foram atendidos. As respostas a estas questões podem ser facilmente verificadas no modelo de decisão exposto no capítulo 4. 


\section{REFERÊNCIAS BIBLIOGRÁFICAS}

ANDERSON, J.R; DILLON, J.L; HARDAKER, B. Agricultural decision analysis. Iowa: Iowa State University Press, 1977. 344p.

AZEVEDO FILHO, A.J.B.V.Seguros fundamentados em índices de produtividade e renda agrícola regional como instrumento para administração de risco no Brasil. Piracicaba: USP/ESALQ/FAPESP/CNPq, 2001. 141p. (Relatório de pesquisa)

AZEVEDO FILHO, A.J.B.V. Análise econômica de projetos: "software" para situações deterministas e de risco envolvendo simulação. Piracicaba, 1988. 127p. Dissertação (MS) - Escola Superior de Agricultura "Luiz de Queiroz", Universidade de São Paulo.

AZEVEDO FILHO, A.J.B.V.; PERES, F.C. Competitividade da cultura da soja em uma empresa da região de Campinas, SP. In: Planejamento da propriedade agrícola: modelos de decisão. Brasília: EMBRAPA, DDT, 1986. p.289-300.

BACHA, E.; GREENBILL, R. 150 anos de café. Rio de Janeiro: M. Martins/E. Johnson, 1992. 118p.

BADER, G.E.; ROSSI, C.A. Focus groups : a step-by-step guide. San Diego: The Bader Group, 1999. 39p.

BARTHOLO, G.F.; GUIMARÃES, P.T.G. Cuidados na colheita, no preparo e no armazenamento do café (Coffea arabica L.). Informe Agropecuário, v.14, n.162, p.33-44, 1989. 
BARTHOLO, G.F.; GUIMARÃES, P.T.G. Cuidados na colheita e preparo do café. Informe Agropecuário, v.18, n.187, p.33-42, 1997.

BARTHOLO, G.F.; MELO, B. de; MENDES, A.N.G. Evolução na adoção de espaçamentos na cultura do café. Informe Agropecuário, v.19, n.193, p.49-60, 1998.

BRANDO, C.E.J. Cereja descascado, desmucilado, fermentado, despolpado ou lavado? In: CONGRESSO BRASILEIRO DE PESQUISAS CAFEEIRAS, 25., Franca, 1999. Anais. Rio de Janeiro: MAA/PROCAFÉ, 1999. p.342-346.

CARLINI-COTRIM, B. Potencialidades da técnica qualitativa grupo focal em investigações sobre abuso de substâncias. Saúde Pública, v.30, n.3, p.285-293, 1996.

CARVALHO, G.R. Cresce participação do café brasileiro no exterior. Gazeta Mercantil, São Paulo, 01 nov. 2001. p.B14.

CARVAlHO, G.R.; FALCO, L.; GUIMARÃES, R.J.; MENDES, A.N.G. Café adensado: alternativa para a moderna cafeicultura. Lavras: Universidade Federal de Lavras, 1997a. 27p. (Boletim Técnico, 6/19)

CARVALHO, V.D. Cafeicultura empresarial: produtividade e qualidade: qualidade do café. Lavras, 1997c. 73p. Monografia (Pós-Graduação "Latu-Sensu” por Tutoria à Distância) - Universidade Federal de Lavras.

CARVALHO, V.D.; CHAGAS, S.J.R.; SOUZA, S.M.C. Fatores que afetam a qualidade do café. Informe Agropecuário, v.18, n.187, p.5-20, 1997 b.

COFFEE BUSINESS. Anuário estatístico do café 1999-2000. Rio de Janeiro, 2000. v.5. 
CRUZ, E.R.C. Aspectos teóricos sobre incorporação de risco em modelos de decisão. In: Risco em modelos de decisão na agricultura. Brasília: EMBRAPA, DEP, 1986. p.13-31.

FARINA, E.M.Q.; SAES, M.S.M. O agribusiness do café no Brasil. São Paulo, Milkbizz, 1999. 230p.

FAYA, J.F.M.; HONDA, A.I.; SARTORI, S.; BASTOS, M.V. Eficiência da colheita mecânica nas variedades Mundo Novo e Catuaí em diferentes condições de lavoura. In: CONGRESSO BRASILEIRO DE PESQUISAS CAFEEIRAS, 7., Araxá, 1979. Anais. Rio de Janeiro: MIC/IBC, GERCA, 1979. p.267-272.

FERREIRA FILHO, J.B.S. As origens da crise e o futuro da cafeicultura brasileira e mundial: de onde viemos, para onde vamos? Preços Agrícolas, v.77, n.7, p.4-9, mar. 1993.

FRIEDMAN, M.; SAVAGE, L.J. The utility analysis of choices involving risk. Journal of Political Economy, v.56, n.4, p.279-304, 1948.

GARCIA, J.C.; CRUZ, J.C. Seleção, pela dominância estocástica, de práticas agrícolas eficientes com respeito ao risco: uma aplicação para a cultura de milho. Revista de Economia Rural, v.17, n.2, p.131-142, abr./jun. 1979.

GROSSI, J.C. Avaliação do custo da colheita mecanizada em relação a manual, na região de Patrocínio-MG. In: CONGRESSO BRASILEIRO DE PESQUISAS CAFEEIRAS, 26., Águas de Lindóia, 1996. Anais. Rio de Janeiro MAARA/PROCAFÉ/DENAC, 1996. p.115-116.

GROSSI, J.C. Administrar o agronegócio do café é o maior desafio. Preços Agrícolas, v.12, n.142, p.8, ago. 1998.

HAMMOND, J.S; KEENEY, R.L.; RAIFFA, H. Smart choices: a practical guide to making better decisions. Boston: Harvard Business School Press, 1998a. 244p. 
HAMMOND, J.S.; KEENEY, R.L.; RAIFFA, H. The hidden traps in decision making. Harvard Business Review, v.76, n.5, p.47-57, Sep./Oct. 1998b.

HOWARD, R.A. From influence to relevance to knowledge. In: OLIVER, R.; SMITH, J. (Ed.). Influence diagrams, belief nets and decision analysis. New York: John Wiley \& Sons, 1990. p.3-23.

HOWARD, R.A.; MATHERSON, J.E. Influence diagrams. In: HOWARD, R.A.; MATHERSON, J.E. (Ed.). The principle and application of decision analisys. Menlo Park: The Strategic Decision Group, 1984. v.1-2.

HILLIER, F.S.; LIEBERMAN, G.J. Introdução a pesquisa operacional. Rio de Janeiro: Campos; São Paulo: EDUSP, 1988. 805p.

KASHIMA,T.; HONDA, A.I.; FAVA, J.F.M.; BASTOS, M.V.; SARTORI,S. A colheita mecânica do café. In: RENA, A.B.; MALAVOLTA, E.; ROCHA, M. Cultura do cafeeiro: fatores que afetam a produtividade. Piracicaba: Patafos, 1986. p.409-422.

KRUEGER, R.A. Focus groups: a pratical guide for applied research. Thousand Oaks: Sage Publications, 1994. 255p.

LEITE, R.A. Qualidade tecnológica do café (Coffea arabica L.) pré-processado por "via seca" e "via úmida". Viçosa, 1998. 54p. Dissertação (M.S.) - Universidade Federal de Viçosa.

LENCE, S.H. The economic value of minimum-variance hedges. American Journal of Agricultural Economics, v.77, n.2, p.353-364, May 1995.

MARKOWITZ, H.M.; REID, D.W.; TEW, B.V. The value of a blank check. The Journal of Portfolio Management, v.20, n.4, p.82-91, Summer 1994.

MARTIN, N.B.; VEGRO, C.L.R.; MORICOCHI, L. Custos e rentabilidade de diferentes sistemas de produção de café. Informações Econômicas, v.25, n.8, p.131-142, ago. 1995. 
MATIELLO, J.B. Sistemas de produção na cafeicultura moderna. Rio de Janeiro: MAARA/ PROCAFÉ, abr. 1995. 102p.

MATIOLI, C.S. Irrigação suplementar de cana-de-açúcar: modelo de análise de decisão para o estado de São Paulo: Piracicaba, 1998. 122p. Tese (Doutorado) - Escola Superior de Agricultura “Luiz de Queiroz”, Universidade de São Paulo.

MELLO, E.V. A cafeicultura no Brasil. In: ZAMBOLIM, L. Tecnologias de produção de café com qualidade. Viçosa: Editora UFV, 2001. p.565-606.

MIGUEL, A.E.; PAUlinO, A.J.; MATIELlO, J.B.; BRAGANÇA, J.B. Comparação entre sistemas de plantio concentrado e plantio tradicional. In: CONGRESSO BRASILEIRO DE PESQUISAS CAFEEIRAS, 7., Araxá, 1992. Anais. Rio de Janeiro: IBC, GERCA, 1979. p.204-206.

MIGUEL, A.E.; MATIELlO, J.B.; ALMEIDA, S.R. Espaçamento e condução do cafeeiro. In: RENA, A.B.; MALAVOLTA, E.; ROCHA, M. Cultura do cafeeiro: fatores que afetam a produtividade. Piracicaba: Patafos, 1986. p.303-322.

MINAS GERAIS. Secretaria de Estado da Agricultura, Pecuária e Abastecimento. Cenário futuro para a cadeia produtiva do café em Minas Gerais. Belo Horizonte, 1995. v.7.

MORICOCHI, L.; MARTIN, N.B. Acordos internacionais e mercado de café. Informações Econômicas, v.24, n.7, p.17-29, jul. 1994.

NACIF, A.P. Fenologia e produtividade do cafeeiro (Coffea arabica L.) cv. Catuaí sob diferentes densidades de plantio e doses de fertilizante, no cerrado de PatrocínioMG. Viçosa, 1997. 124 p. Tese (Doutorado) - Universidade Federal de Viçosa.

NEVES, E.M. Biotecnologia e defesa fotossanitária na citricultura: economicidade de uso de fatores de produção em condições de risco. Piracicaba: ESALQ/CNPq, 2000. 69p. (Relatório de pesquisa) 
PACHECO, J.A.C. Modelos de decisão na analise econômica de experimentos agrícolas. Piracicaba, 1985. 111p. Dissertação (MS) - Escola Superior de Agricultura "Luiz de Queiroz”, Universidade de São Paulo.

PÁDUA, T.S. Espaçamento econômico na cultura do cafeeiro (Coffea arabica, L.): um estudo no sul de Minas Gerais. Lavras, 1998. 62p. Dissertação (M.S.) Universidade Federal de Lavras.

PERES, F.C. Confinamento de gado de corte: um modelo de análise de decisão. Piracicaba, 1990. 74p. Tese (Livre-Docência) - Escola Superior de Agricultura "Luiz de Queiroz", Universidade de São Paulo.

PERES, F.C. Modelo de decisão na minimização de riscos de preço do café. Preços Agrícolas, v.11, n.133, p.7-12, nov. 1997.

RUIZ, J.A. Metodologia científica: guia para eficiência nos estudos. São Paulo: Atlas, 1982. 170p.

SALOMÃO, C.C. Sistemas de plantio direto e convencional: um enfoque de análise de decisão: Piracicaba, 1990. 127p. Dissertação (M.S.) - Escola Superior de Agricultura "Luiz de Queiroz", Universidade de São Paulo.

SETTE, R.S. Marketing para jovens consumidores de café: estratégias para o mercado brasileiro. São Paulo, 1999. 167p. Tese (Doutorado) - Escola de Administração de Empresas de São Paulo, Fundação Getúlio Vargas.

SHACHTER, R.D. Evaluating influence diagrams. Operations Research, v.34, n.6, p.871-882, 1986.

SHACHTER, R.D. Probabilistic inference and influence diagrams. Operations Research, v.34, n.6, p.589-604, 1987. 
SIQUEIRA, R.; ANDROCIOLI FILHO, A.; CARAMORI, M.A.; PAVAN, M.A.; CHAVES, J.C.D. Efeito de oito densidades de plantio na produtividade de três cultivares de café (Coffea arabica L.), do híbrido "Icatu". In: CONGRESSO BRASILEIRO DE PESQUISAS CAFEEIRAS, 16., Espírito Santo do Pinhal, 1990. Anais. Rio de Janeiro: IBC, GERCA, 1990. p.86.

STRENGER, R.G. Lei da oferta e da procura? Jornal Coffee Business, v.9, n.512, p.3, 2001.

TOLEDO, A.R.; MIGUEL, A.E.; MATIELLO, J.B. Estudo de espaçamentos na linha no plantio do cafeeiro Mundo Novo LCP 379/19: resultado de 8 colheitas. In: CONGRESSO BRASILEIRO DE PESQUISAS CAFEEIRAS, 18., Araxá, 1992. Anais. Rio de Janeiro: MAARA/PROCAFÉ, 1992. p.118-119.

VIANA, A.S.; CAMARGO, A.P. de; FREIRE, D. Efeito de espaçamentos progressivos na produção de café por cova e por área. In: CONGRESSO BRASILEIRO DE PESQUISAS CAFEEIRAS, 11., Londrina, 1984. Anais. Rio de Janeiro: IBC, Gerca, 1984. p.171-173.

WESTPHAL, M.F.; BÓGUS, C.M.; FARIA, M.M. Grupos focais: experiências precursoras em programas educativos em saúde no Brasil. Boletim de la Oficina Sanitaria Panamericana, v.120, n.6, p.472-482, 1996.

YARRI, M.E. Some remarks on measures of risk aversion and on their uses. Journal of Economic Theory, v.1, n.3, p.315-329, Oct. 1969. 